\title{
Improved retrieval of direct and diffuse downwelling surface shortwave flux in cloudless atmosphere using dynamic estimates of aerosol content and type: application to the LSA-SAF project
}

\author{
X. Ceamanos, D. Carrer, and J.-L. Roujean \\ CNRM-GAME, UMR3589, Météo-France/CNRS, Toulouse, France \\ Correspondence to: X. Ceamanos (xavier.ceamanos@meteo.fr) \\ Received: 26 February 2014 - Published in Atmos. Chem. Phys. Discuss.: 26 March 2014 \\ Revised: 2 July 2014 - Accepted: 9 July 2014 - Published: 15 August 2014
}

\begin{abstract}
Downwelling surface shortwave flux (DSSF) is a key parameter to addressing many climate, meteorological, and solar energy issues. Under clear sky conditions, DSSF is particularly sensitive to the variability both in time and space of the aerosol load and chemical composition. Hitherto, this dependence has not been properly addressed by the Satellite Application Facility on Land Surface Analysis (LSA-SAF), which operationally disseminates instantaneous DSSF products over the continents since 2005 considering constant aerosol conditions. In the present study, an efficient method is proposed for DSSF retrieval that will overcome the limitations of the current LSA-SAF product. This method referred to as SIRAMix (Surface Incident Radiation estimation using Aerosol Mixtures) is based upon an accurate physical parameterization coupled with a radiative transfer-based look up table of aerosol properties. SIRAMix considers a tropospheric layer composed of several major aerosol species that are conveniently mixed to reproduce real aerosol conditions as best as possible. This feature of SIRAMix allows it to provide not only accurate estimates of global DSSF but also the direct and diffuse DSSF components, which are crucial radiative terms in many climatological applications. The implementation of SIRAMix is tested in the present article using atmospheric analyses from the European Center for Medium-Range Weather Forecasts (ECMWF). DSSF estimates provided by SIRAMix are compared against instantaneous DSSF measurements taken at several ground stations belonging to several radiation measurement networks. Results show an average root mean square error (RMSE) of $23.6,59.1$, and $44.9 \mathrm{~W} \mathrm{~m}^{-2}$ for global, direct, and diffuse DSSF, respectively. These scores decrease the average RMSE obtained for the current LSA-SAF product by $18.6 \%$,
\end{abstract}

which only provides global DSSF for the time being, and, to a lesser extent, for the state of the art in the matter of DSSF retrieval (RMSE decrease of 10.9, 6.5, and $19.1 \%$ for global, direct, and diffuse DSSF with regard to the McClear algorithm). The main limitation of the proposed approach is its high sensitivity to the quality of the ECMWF aerosol inputs, which is proved to be sufficiently accurate for reanalyses but not for forecast data. Given the proximity of DSSF retrieval to the modeling of the atmospheric direct effect, SIRAMix is also able to quantify the direct radiative forcing at the surface due to a given atmospheric component (e.g., gases or aerosols).

\section{Introduction}

Downwelling surface shortwave flux (DSSF) is defined as the irradiance in the solar spectrum reaching the Earth's surface per unit of surface. Knowing the spatial distribution and temporal evolution of DSSF is essential for understanding climate processes at the surface/atmosphere interface. For example, Soon and Legates (2013) present empirical evidence for a direct relationship between DSSF and the surface temperature gradient observed from the Equator to the Arctic Pole. Also, DSSF is directly related to the atmospheric radiative forcing at the surface ( $\mathrm{Bi}$ et al., 2013) and to the field of solar energy and photovoltaic power plants (Yoshida et al., 2013). In the absence of clouds, DSSF is mainly driven by solar inclination, water vapor content, and atmospheric aerosols. The latter particles generally have opposite effects on the direct and diffuse radiative components that constitute 
the so-called global DSSF. On the one hand, an enhanced presence of aerosols results in less direct DSSF, leading to a mitigation of the air temperature increase caused by greenhouse gases (Andreae, 1995). On the other hand, high aerosol loads increase the diffuse DSSF, which has proved to be of great importance for vegetation photosynthesis (Mercado et al., 2009).

The estimation of DSSF on a large scale has been addressed during the last decades following two different types of approaches. The first family is made of methods based on extensive look up tables (LUT) storing DSSF values that are pre-computed using radiative transfer codes for multiple atmospheric situations. Examples are the approaches used by the Climate Satellite Application Facility (CM-SAF) (Mueller et al., 2009), the Global LAnd Surface Satellite project (GLASS) (Liang et al., 2013), or the recent McClear algorithm (Lefèvre et al., 2013). Second, physical parameterizations are used to quantify DSSF in combination with several atmospheric inputs in a more computationally efficient manner. Examples on this second family of methods can be found in Pinker et al. (1995) and Gueymard (2003).

An example of this second group of methods is the approach implemented in the operational system of the Satellite Application Facility on Land Surface Analysis (LSA-SAF, http://landsaf.meteo.pt) program of EUMETSAT (European Organization for the Exploitation of Meteorological Satellites) (Trigo et al., 2011). Since 2005 the LSA-SAF method (Geiger et al., 2008b) is used to generate maps of global DSSF using observations from the Meteosat Second Generation (MSG) series of geostationary satellites (Schmetz et al., 2002) and near real time analyses of atmospheric gases from the European Center for Medium-Range Weather Forecasts (ECMWF). Albeit this LSA-SAF product has proved to be highly accurate (Ineichen et al., 2009; Roerink et al., 2012; Moreno et al., 2013), it still shows some limitations under clear sky conditions. For example, the adoption of a static aerosol optical depth (AOD) does not match the variability of aerosols in time and space (Bevan et al., 2012). Also, the assumption of a continental aerosol type does not describe accurately enough the usual mixture of natural and anthropogenic aerosol species on Earth (Koepke et al., 1997; Dentener et al., 2006).

The accurate consideration of aerosol radiative effects to quantify incoming radiation at the surface is a historic claim of the climate and meteorological communities (Gueymard, 2003; Varotsos et al., 2006). However, the description of aerosol properties had to be necessarily simplified due to the poor knowledge on aerosols at broad scale. To cope with the estimation of solar irradiance at the surface, various hypotheses have been made such as considering aerosols to be invariant in time and space (Deneke et al., 2005; Geiger et al., 2008b), to arise from climatology (Mueller et al., 2009), to correspond to a single aerosol type (Liang et al., 2013), or to depend on geographical location (Psiloglou and Kambezidis, 2007). To our knowledge, the McClear algorithm (Lefèvre et al., 2013) is the only method for retrieval of DSSF under clear sky using dynamic aerosol data.

The LSA-SAF algorithm for DSSF retrieval uses two separate methods to deal with cloudy or clear sky conditions (Geiger et al., 2008b). The main objective of this article is to propose a new method that would favorably replace the current algorithm in the latter case, that is, under a cloudless atmosphere. The proposed approach referred to as SIRAMix (Surface Incident Radiation estimation using Aerosol Mixtures) carries out an enhanced depiction of the aerosol radiative effects by considering an aerosol layer made of a mixture of different components. Among other inputs, dynamic information on aerosol content and type is used by SIRAMix. In addition to global DSSF, new products of direct and diffuse DSSF are also generated. The radiation products generated by SIRAMix will be used in the future as forcing in surface, atmospheric and weather forecast models, as it is done in (Szczypta et al., 2012; Carrer et al., 2012; QuintanaSeguí et al., 2010). Due to the proximity of DSSF retrieval to the modeling of the atmospheric direct effect, SIRAMix also presents the capability of quantifying the radiative forcing at the surface due to a given atmospheric component. Given its high speed and accuracy, SIRAMix can advantageously replace sophisticated yet heavy radiative transfer codes or algorithms.

The present article is organized as follows. First, the proposed method SIRAMix is detailed in Sect. 2, as well as its implementation using atmospheric analyses from the ECMWF. Experiments are introduced in Sect. 3 and results are reported in Sect. 4. Eventually, major findings are discussed in Sect. 5 and conclusions are drawn in Sect. 6.

\section{Methods}

SIRAMix consists of an accurate physical parameterization that separately calculates the instantaneous direct and diffuse components of the DSSF. This parameterization presented in Sect. 2.1 results from a combination of existent expressions and new developments. The upgrade consists of an accurate parameterization for the diffuse incoming radiation and the consideration of the aerosol effects resulting from an aerosol layer made of a mixture of several components. As explained in Sect. 2.2, this is achieved by combining appropriate physical parameterizations with a look up table of precomputed aerosol radiative quantities. The implementation of SIRAMix using analyses from the ECMWF is detailed in Sect. 2.3. Finally, the determination of clear sky instants of time is explained in Sect. 2.4.

\subsection{Estimation of DSSF under clear sky conditions}

First of all, it is important to remark that capital letters will be used in the present article for shortwave radiative quantities, whereas small letters will be retained for spectral quantities. 


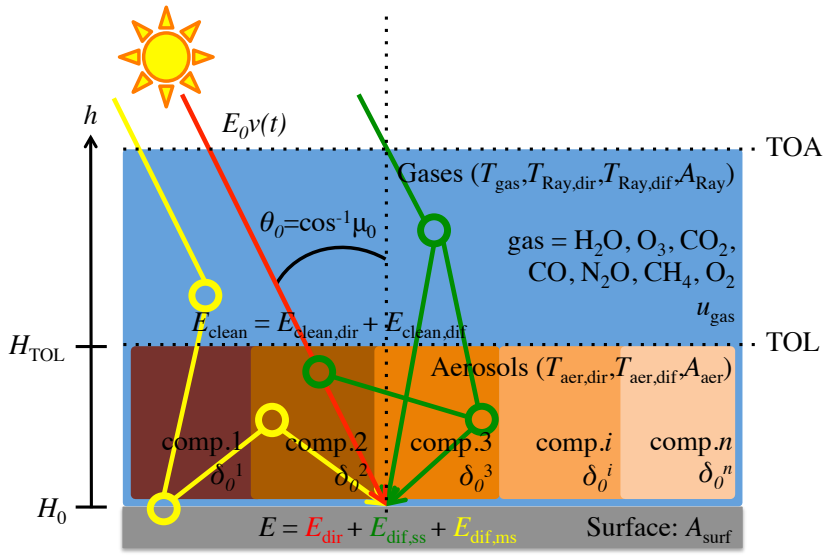

Figure 1. Scheme of the solar irradiance reaching the Earth's surface or DSSF $(E)$. Note that the use of separate blocks for each aerosol component (referred to as comp. $i$ in the figure) is done for the sake of illustration, as the $\mathrm{n}$ species are mixed forming a homogeneous aerosol layer. The description of each quantity in the figure may be found in the text.

Also, the term DSSF will stand hereafter for downwelling shortwave surface flux under clear sky conditions only.

Figure 1 shows the atmosphere/surface scheme contemplated in SIRAMix. A gaseous atmosphere spans from the surface $\left(H_{0}\right)$ to the top-of-atmosphere (TOA) level. This layer comprises the most predominant gases, that is, water vapor $\left(\mathrm{H}_{2} \mathrm{O}\right)$, ozone $\left(\mathrm{O}_{3}\right)$, carbon dioxide $\left(\mathrm{CO}_{2}\right)$, carbon monoxide $(\mathrm{CO})$, nitrous oxide $\left(\mathrm{N}_{2} \mathrm{O}\right)$, methane $\left(\mathrm{CH}_{4}\right)$, and oxygen $\left(\mathrm{O}_{2}\right)$. A tropospheric layer formed by a mixture of $n$ basic aerosol components co-exists with the gaseous layer from the surface to the top of layer (TOL) level $\left(H_{\mathrm{TOL}}\right)$. Each aerosol component $i$ is characterized by its own AOD at $550 \mathrm{~nm}\left(\delta_{0}^{i}\right)$. The total AOD of the aerosol layer corresponds to the sum of the individual opacities (i.e., $\delta_{0}=\sum \delta_{0}^{i}$ ). More details on the aerosol layer are given in Sect. 2.2.1. Finally, a surface layer characterized by its albedo $\left(A_{\text {surf }}\right)$ is found at the bottom boundary of the atmosphere.

The DSSF (or $E$ ) is defined as the instantaneous spectral downwelling solar (or shortwave) radiative flux per unit of surface that arrives to the surface $(e(\lambda))$ integrated over the shortwave spectrum

$E=\int_{\lambda_{1}}^{\lambda_{2}} e(\lambda) \mathrm{d} \lambda$,

where $\lambda_{1} \simeq 0.25 \mu \mathrm{m}$ and $\lambda_{2} \simeq 4.0 \mu \mathrm{m}$. Units of instantaneous DSSF are watts per square meter $\left(\mathrm{W} \mathrm{m}^{-2}\right)$.

The global DSSF can be expressed as the sum of two radiative components

$E=E_{\mathrm{dir}}+E_{\mathrm{dif}}$,

where the direct DSSF $\left(E_{\mathrm{dir}}\right)$ results from the solar irradiance coming from the direction of the Sun (see red arrow in Fig. 1) and the diffuse DSSF ( $\left.E_{\mathrm{dif}}\right)$ stands for the portion of irradiance that comes from other directions due to aerosol and molecular (i.e., Rayleigh) scattering. The diffuse DSSF can be single $\left(E_{\mathrm{dif}, \mathrm{ss}}\right)$, when there is no previous interaction with the surface (see green arrow), or multiple $\left(E_{\mathrm{dif}, \mathrm{ms}}\right)$, after one or several bounces between the surface and the atmosphere media (see yellow arrow).

\subsubsection{Expression for direct DSSF}

The direct DSSF in SIRAMix is expressed according to Psiloglou and Kambezidis (2007) as

$$
\begin{aligned}
E_{\text {dir }} & =E_{\text {clean,dir }} T_{\text {aer,dir }} \\
& =E_{0} v(t) \mu_{0} T_{\mathrm{H}_{2} \mathrm{O}} T_{\mathrm{O}_{3}} T_{\mathrm{mg}} T_{\text {Ray,dir }} T_{\text {aer,dir }},
\end{aligned}
$$

where $E_{\text {clean,dir }}$ stands for the direct DSSF that would reach the surface of the Earth in a gaseous atmosphere free of aerosol particles.

The flux reaching the TOA (see Fig. 1) depends on the solar constant $\left(E_{0}\right)$, which is set to $1367 \mathrm{Wm}^{-2}$ according to the World Meteorological Organization (WMO, 2006), the quantity $\mu_{0}$, which is the cosine of the solar zenith angle (SZA or $\theta_{0}$ ), and the factor $v(t)$, which accounts for the varying distance of the Sun as a function of time $(t)$ according to (Spencer, 1971)

$$
\begin{aligned}
& v(t)=1.00011+0.034221 \cos \Gamma \\
& \quad+0.00128 \sin \Gamma+0.000719 \cos 2 \Gamma+0.000077 \sin 2 \Gamma,
\end{aligned}
$$

where $\Gamma$ (in radians) is the day angle, which is given by

$\Gamma=\frac{2 \pi\left(k_{i}-1\right)}{365}$,

where the day number of the year $\left(k_{i}\right)$ ranges from 1 (1 January) to 365 (31 December). Leap years are considered to have 365 days.

As shown in Fig. 1, the solar flux at the TOA is attenuated by gas absorption through transmission functions for water vapor $\left(T_{\mathrm{H}_{2} \mathrm{O}}\right)$, ozone $\left(T_{\mathrm{O}_{3}}\right)$, and uniformly mixed gases ( $T_{\mathrm{mg}}=T_{\mathrm{CO}_{2}} T_{\mathrm{CO}} T_{\mathrm{N}_{2} \mathrm{O}} T_{\mathrm{CH}_{4}} T_{\mathrm{O} 2}$ ). Also, a portion of the shortwave irradiance is diverted from the direct path through Rayleigh scattering ( $\left.T_{\text {Ray,dir }}\right)$. The remainder flux at the TOL level is attenuated by aerosol extinction (scattering and absorption) before reaching the surface by means of the transmittance $T_{\text {aer,dir }}$.

Transmittance functions for gases are adopted from Psiloglou and Kambezidis (2007)

$$
T_{\mathrm{gas}}=1-\frac{a m^{\prime} u_{\mathrm{gas}}}{\left(1+b m^{\prime} u_{\mathrm{gas}}\right)^{c}+d m^{\prime} u_{\mathrm{gas}}},
$$

where subindex gas may stand for any of the seven atmospheric gases in Fig. 1. Coefficients $a, b, c, d$ depend on the extinction process of each gas and are given in Table 1 . These transmittance functions were derived from radiative transfer 
Table 1. Coefficients $a, b, c$ and $d$ used to compute shortwave transmittances for predominant atmospheric gases using Eq. (6). The amount of each atmospheric gas $\left(u_{\text {gas }}\right)$ considered in SIRAMix is also given. All values are taken from Psiloglou and Kambezidis (2007) and Psiloglou et al. (1995a).

\begin{tabular}{lccccc}
\hline & $a$ & $b$ & $c$ & $d$ & $u_{\text {gas }}$ \\
\hline $\mathrm{H}_{2} \mathrm{O}$ & 3.0140 & 119.300 & 0.6440 & 5.8140 & variable \\
$\mathrm{O}_{3}$ & 0.2554 & 6107.26 & 0.2040 & 0.4710 & variable \\
$\mathrm{CO}_{2}$ & 0.0721 & 377.890 & 0.5855 & 3.1709 & 350 \\
$\mathrm{CO}$ & 0.0062 & 243.670 & 0.4246 & 1.7222 & 0.075 \\
$\mathrm{~N}_{2} \mathrm{O}$ & 0.0326 & 107.413 & 0.5501 & 0.9093 & 0.28 \\
$\mathrm{CH}_{4}$ & 0.0192 & 166.095 & 0.4221 & 0.7186 & 1.60 \\
$\mathrm{O}_{2}$ & 0.0003 & 476.934 & 0.4892 & 0.1261 & $2.095 \times 10^{5}$ \\
\hline
\end{tabular}

simulations in the shortwave range by Psiloglou et al. (1994, 1995a, 1996) and were found to be accurate with regard to other parameterizations by Gueymard (2003). Quantity $u_{\text {gas }}$ in Eq. (6) represents the absorption amount in a vertical column for a given gas in units of atm-cm. In the first version of SIRAMix, this quantity is fixed for minor atmospheric gases (see Table 1) and is variable for water vapor and ozone contents, making $u_{\mathrm{H}_{2} \mathrm{O}}$ and $u_{\mathrm{O}_{3}}$ two inputs of the proposed method.

The optical air mass $(m)$ at standard pressure conditions is given by the formula of Kasten and Young (1989)

$m=\left[\mu_{0}+0.50572\left(96.07995-\theta_{0}\right)^{-1.6364}\right]^{-1}$,

which takes into account the Earth's curvature and is accurate for any air mass up to $\theta_{0}<85^{\circ}$ with an error of less than $0.5 \%$. The proposed method SIRAMix takes into account the effect of altitude on gas absorption by using the pressurecorrected air mass $\left(m^{\prime}\right)$

$m^{\prime}=m\left(\frac{P}{P_{0}}\right)$,

where $P$ is the atmospheric pressure at the surface altitude in $\mathrm{Pa}$ and $P_{0}=101325 \mathrm{~Pa}$ is the mean atmospheric pressure at sea level. Air pressure above sea level is classically computed as

$$
P=P_{0}\left(1-2.25577 \times 10^{-8} H_{0}\right)^{5.25588},
$$

where $H_{0}$ is the altitude above sea level in kilometers (see Fig. 1).

Eventually, the direct transmittance due to Rayleigh scattering is adopted from Psiloglou et al. (1995b)

$$
\begin{aligned}
& T_{\text {Ray,dir }}= \\
& \exp \left[-0.1128 m^{\prime 0.8346}\left(0.9341-m^{\prime 0.9868}+0.9391 m^{\prime}\right)\right] .
\end{aligned}
$$

\subsubsection{Expression for diffuse DSSF}

The diffuse DSSF is computed by SIRAMix as the sum of single scattering irradiance $\left(E_{\mathrm{dif}, \mathrm{ss}}\right)$ and a multiple scattering component ( $\left.E_{\text {dif,ms }}\right)$ (see Fig. 1)

$E_{\mathrm{dif}}=E_{\mathrm{dif}, \mathrm{ss}}+E_{\mathrm{dif}, \mathrm{ms}}$.

Single scattering diffuse irradiance can be computed by multiplying the global (direct plus diffuse) flux reaching the TOL level by the diffuse aerosol transmittance=

$E_{\text {dif,ss }}=E_{\text {clean }} T_{\text {aer,dif }}=\left(E_{\text {clean,dir }}+E_{\text {clean,dif }}\right) T_{\text {aer,dif }}$.

The diffuse downwelling solar irradiance at the TOL can be expressed as

$E_{\text {clean, dif }}=E_{0} v(t) \mu_{0} T_{\mathrm{H}_{2} \mathrm{O}} T_{\mathrm{O}_{3}} T_{\mathrm{mg}} T_{\text {Ray,dif }}$,

where the diffuse transmittance due to Rayleigh scattering reads (Bird and Hulstrom, 1981)

$T_{\text {Ray,dif }}=0.5\left(1-T_{\text {Ray,dir }}\right)$,

and factor 0.5 stands for the forward scattering fraction (Mengüç and Viskanta, 1983), meaning that a half of radiation scattered by molecules goes downward due to the isotropic nature of Rayleigh scattering.

Using Eqs.( 4), (13) and (14) into Eq. (12), the single scattering diffuse irradiance finally reads

$$
\begin{aligned}
E_{\mathrm{dif}, \mathrm{ss}}= & E_{0} v(t) \mu_{0} T_{\mathrm{H}_{2} \mathrm{O}} T_{\mathrm{O}_{3}} T_{\mathrm{mg}} \\
& \left(T_{\text {Ray }, \text { dir }}+0.5\left(1-T_{\text {Ray,dir }}\right)\right) T_{\text {aer,dif }} .
\end{aligned}
$$

The use of a diffuse transmittance for aerosol particles ( $\left.T_{\text {aer,dif }}\right)$ in SIRAMix represents an advantage compared to other methods (Yang et al., 2006; Psiloglou and Kambezidis, 2007), which derive the diffuse transmittance from the direct term, similar to what it is done for Rayleigh scattering in SIRAMix (see Eq. 14). In fact, the latter approach may result in some limitations, as the complexity of aerosol scattering disables a direct link between direct and diffuse aerosol transmittances (Kokhanovsky et al., 2005).

Finally, the diffuse DSSF coming from multiple scattering is classically expressed as (Sobolev, 1972)

$E_{\mathrm{dif}, \mathrm{ms}}=\left(E_{\mathrm{dir}}+E_{\mathrm{dif}, \mathrm{ss}}\right) \frac{A_{\mathrm{surf}} A_{\mathrm{atm}}}{1-A_{\mathrm{surf}} A_{\mathrm{atm}}}$,

where $A_{\text {surf }}$ and $A_{\text {atm }}$ are, respectively, the shortwave spherical albedos of the surrounding surface and the atmosphere when illuminated from below. The denominator of Eq. (16) takes into account multiple reflection of photons between the surface and the atmosphere. The albedo of the atmosphere $\left(A_{\text {atm }}\right)$ under clear sky conditions is approximated by

$A_{\text {atm }} \simeq A_{\text {aer }}+A_{\text {Ray }}$,

where $A_{\text {Ray }}$ is set to 0.0685 after Lacis and Hansen (1974). 


\subsection{Quantification of the aerosol influence}

Expressions for radiative quantities related to aerosols (i.e., $T_{\text {aer,dir }}, T_{\text {aer,dif }}$, and $\left.A_{\text {aer }}\right)$ are given in the present section to complete the physical parameterization for DSSF detailed above. Their formulation represents one of the main novelties of the proposed approach. First, the aerosol layer considered in SIRAMix and schemed in Fig. 1 is further detailed.

\subsubsection{Definition of the aerosol layer}

For the implementation of SIRAMix in this article, it is assumed that all aerosol scenarios on Earth can be reproduced by mixing five standard aerosol species (i.e., $n=5$ in Fig. 1). This vision is supported by the fact that aerosols are very frequently a mixture of different chemical components (Dubovik et al., 2002; Dentener et al., 2006). The five aerosol components used in SIRAMix are borrowed from the Global Aerosol Data Set (GADS) (Koepke et al., 1997), which makes available optical properties for each one of them. More details on the GADS data base are found in Appendix A. It is worth noting here that SIRAMix is independent of GADS, as it can be coupled with other available aerosol data bases. In this article, SIRAMix considers aerosols made of

1. insoluble particles modeled by the GADS component INSO,

2. water soluble particles modeled by the GADS component WASO,

3. black carbon particles modeled by the GADS component SOOT,

4. fine and coarse sea salt particles modeled by a combination of the GADS components SSAM and SSCM (hereafter referred to as component SSALL),

5. fine, medium-sized and coarse dust particles modeled by a combination of the GADS components MINM, MIAM, and MICM (hereafter referred to as component MIALL).

Table 2 details the single scattering albedo $\left(\omega_{0}\right)$ and hygroscopicity of each of the five resulting aerosol components. It is worth remembering here that hygroscopic aerosols, oppositely to hydrophobic, are prone to combine with water particles, thus modifying their optical properties.

\subsubsection{Parameterization for the transmittance and albedo of the aerosol layer}

The transmittances and the albedo of the aerosol layer considered in SIRAMix are computed using the approach de-
Table 2. GADS-based aerosol components used in SIRAMix. Data are borrowed from Koepke et al. (1997).

\begin{tabular}{lccccc}
\hline Type of particles & $\begin{array}{c}\text { INSO } \\
\text { Insoluble }\end{array}$ & $\begin{array}{c}\text { WASO } \\
\text { Water- } \\
\text { soluble }\end{array}$ & $\begin{array}{c}\text { SOOT } \\
\text { Soot }\end{array}$ & $\begin{array}{c}\text { SSALL* } \\
\text { Sea salt }\end{array}$ & $\begin{array}{c}\text { MIALL* } \\
\text { Mineral } \\
\text { dust }\end{array}$ \\
\hline $\begin{array}{l}\omega_{0} \text { at } 500 \mathrm{~nm} \\
\text { Hygroscopic }\end{array}$ & $\begin{array}{c}0.72 \\
\text { no }\end{array}$ & $\begin{array}{c}0.98 \\
\text { yes }\end{array}$ & $\begin{array}{c}0.23 \\
\text { no }\end{array}$ & $\begin{array}{c}1.0 \\
\text { yes }\end{array}$ & $\begin{array}{c}0.83 \\
\text { no }\end{array}$ \\
\hline Asterisk $\left(^{*}\right)$ represents that MIALL is the combination of GADS components MINM, MIAM, and
\end{tabular}

MICM, and that SSALL is the combination of GADS components SSAM and SSCM.

scribed in Ceamanos et al. (2014)

$$
\begin{aligned}
T_{\mathrm{aer}, \mathrm{dir}} & =\frac{1}{\Delta_{0}} \sum_{i=1}^{5} \Delta_{0}^{i} T_{\mathrm{aer}, \mathrm{dir}}^{i}, \\
T_{\mathrm{aer}, \mathrm{dif}} & =\frac{1}{\Delta_{0}} \sum_{i=1}^{5} \Delta_{0}^{i} T_{\mathrm{aer}, \mathrm{dif}}^{i}, \\
A_{\mathrm{aer}} & =\frac{1}{\Delta_{0}} \sum_{i=1}^{5} \Delta_{0}^{i} A_{\mathrm{aer}}^{i},
\end{aligned}
$$

where $T_{\text {aer,dir }}^{i}, T_{\text {aer,dif }}^{i}$, and $A_{\text {aer }}^{i}$ are the individual transmittances and albedo corresponding to the aerosol component $i$ evaluated at the total AOD of the aerosol layer $\left(\delta_{0}\right)$. Quantity $\Delta_{0}^{i}$ is the aerosol optical depth of component $i$ in the shortwave spectrum (n.b., $\Delta_{0}=\sum \Delta_{0}^{i}$ ). The approach in Ceamanos et al. (2014) resulted in transmittances and reflectances for a mixed aerosol layer with an average error of, respectively, 0.6 and $7.6 \%$ with regard to exact radiative transfer calculations. This error proved to be up to $20 \%$ lower than when a single aerosol component was considered.

\subsubsection{Look up table for the transmittance and albedo of each aerosol component}

Values of individual transmittances and albedo are precomputed for each of the five aerosol components in SIRAMix and stored in a LUT. For that purpose, the software libRadtran is used (Mayer and Kylling, 2005). More details on this radiative transfer code are given in Sect. 3.1.1.

Transmittances are computed as the ratio of the DSSF considering a gaseous atmosphere and an aerosol layer exclusively made of component $i$, and the DSSF for the same atmosphere free of aerosols (see Eqs. 4 and 12)

$$
\begin{array}{ll}
T_{\text {aer,dir }}^{i}\left(\theta_{0}, \delta_{0}, u_{\mathrm{H}_{2} \mathrm{O}}\right)= & \frac{E_{\text {dir }}^{i}\left(\theta_{0}, \delta_{0}, u_{\mathrm{H}_{2} \mathrm{O}}\right)}{E_{\text {clean, dir }}\left(\theta_{0}, u_{\mathrm{H}_{2} \mathrm{O}}\right)}, \\
T_{\text {aer,dif }}^{i}\left(\theta_{0}, \delta_{0}, u_{\mathrm{H}_{2} \mathrm{O}}\right)=\frac{E_{\text {dif }}^{i}\left(\theta_{0}, \delta_{0}, u_{\mathrm{H}_{2} \mathrm{O}}\right)}{E_{\text {clean }}\left(\theta_{0}, u_{\mathrm{H}_{2} \mathrm{O}}\right)},
\end{array}
$$

where the numerator and denominator quantities are computed with libRadtran. 
Table 3. Inputs used by SIRAMix to generate DSSF in an operational framework.

\begin{tabular}{lll}
\hline Input & Variable & Product source \\
\hline Solar zenith angle & $\theta_{0}$ & MSG ancillary data \\
Surface albedo & $A_{\text {surf }}$ & LSA-SAF \\
Cloud mask & CMa & NWC-SAF \\
Water vapor content & $u_{\mathrm{H}_{2} \mathrm{O}}$ & ECMWF \\
Ozone content & $u_{\mathrm{O}_{3}}$ & ECMWF \\
Aerosol optical depth & $\delta_{0}^{i}$ & MACC-II \\
\hline
\end{tabular}

The shortwave spherical albedo is directly computed by libRadtran as

$A_{\text {aer }}\left(\delta_{0}, u_{\mathrm{H}_{2} \mathrm{O}}\right)=\int_{\lambda_{1}}^{\lambda_{2}} a_{\mathrm{aer}}\left(\delta_{0}, u_{\mathrm{H}_{2} \mathrm{O}}, \lambda\right) \mathrm{d} \lambda$,

where $a_{\text {aer }}$ is the spectral spherical albedo for a given aerosol component.

A default US standard atmosphere (Anderson et al., 1986) is adopted for all simulations to take into account the interaction of gases (especially water vapor) with aerosols. The use of a single atmospheric model is in agreement with Mueller et al. (2009), who found that the impact on DSSF of considering other regional models was negligible. Aerosol transmittances and albedo depend on the amount of aerosol particles through the total AOD at $550 \mathrm{~nm}\left(\delta_{0}\right)$ and the content of atmospheric water vapor $\left(u_{\mathrm{H} 2 \mathrm{O}}\right)$. The latter dependence exists only for the hygroscopic aerosol components WASO and SSALL (see Table 2). In addition, transmittances also depend on the solar zenith angle $\left(\theta_{0}\right)$. In this way, the LUT in SIRAMix is composed of multiple values of $T_{\mathrm{aer}, \mathrm{dir}}^{i}$, $T_{\text {aer,dif }}^{i}$, and $A_{\text {aer }}^{i}$ for each aerosol component (INSO, WASO, SOOT, SSALL, MIALL) and for a comprehensive range of values of AOD at $550 \mathrm{~nm}$ ( $\delta_{0}$ from 0 to 4$)$, solar zenith angle $\left(\theta_{0}\right.$ from 0 to $\left.85^{\circ}\right)$, and water vapor content $\left(u_{\mathrm{H}_{2} \mathrm{O}}\right.$ from 0 to $5 \mathrm{~g} \mathrm{~cm}^{-2}$ ). Interpolation techniques are used to retrieve the transmittance or albedo corresponding to a given atmospheric combination. The generation of the LUT is quite fast (a few minutes for each aerosol component, CPU time) and must be done only once. The reduced size of the LUT (i.e., less than $300 \mathrm{kB}$ ) allows SIRAMix to easily retrieve the necessary aerosol information for each DSSF calculation, making this approach well designed for operational data processing.

\subsection{Inputs}

In the present article, the proposed approach SIRAMix is run using the inputs listed in Table 3, which are available for the whole MSG Earth's disk and are produced regularly in time. The use of the inputs in the parameterization and the LUT of SIRAMix is illustrated in Fig. 2 and explained in the following sections.

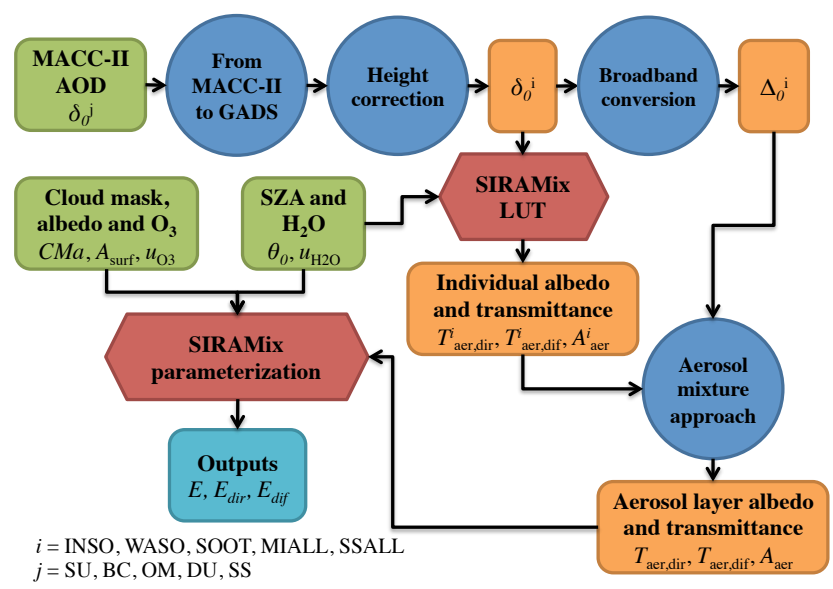

Figure 2. Block scheme of the approach SIRAMix and the use of the inputs. The parameterization and LUT of SIRAMix are illustrated in red boxes. Inputs are drawn in green, intermediate products in orange, and outputs in light blue. The different processing steps are depicted in dark blue circles.

\subsubsection{Cloud mask, surface albedo, and solar zenith angle}

First, the cloud mask from the Nowcasting Satellite Application Facility (NWC-SAF) based on MSG data (Derrien and Le Gléau, 2005) is used in SIRAMix to select only clear sky situations (see Sect. 2.4 for more details). The reflectivity of the surface surrounding a given target is characterized by the shortwave spherical albedo produced by the LSA-SAF project (Geiger et al., 2008a). This product is suitable to be used in the SIRAMix parameterization (see Fig. 2) to simulate multiple scattering effects due to its low uncertainty ( $\sim 5 \%$ error) measured against the surface albedo produced by the MODIS (Moderate-Resolution Imaging Spectroradiometer) team (Carrer et al., 2010b). Finally, accurate values of solar zenith angle from the MSG ancillary data (Schmetz et al., 2002) are used in the SIRAMix parameterization and LUT.

\subsubsection{Water vapor and ozone content}

Fields of atmospheric water vapor $\left(u_{\mathrm{H}_{2} \mathrm{O}}\right)$ and ozone $\left(u_{\mathrm{O}_{3}}\right)$ columnar contents produced by the Integrated Forecast System (IFS) of the ECMWF are used as inputs. Furthermore, analyses of water vapor serve to extract the necessary information from the SIRAMix LUT according to the aerosol hygroscopicity (see Fig. 2). IFS atmospheric fields are available every 3 hours and at global scale with a spatial resolution of $1.125^{\circ} \times 1.125^{\circ}$. Despite an overall good accuracy, some inaccuracies may exist in these data according to Oikonomou and O'Neill (2006), who found a positive bias of 5-10\% for ozone and a negative bias of 15-20\% for water vapor in comparison with values derived from independent remote sensing observations. 


\subsubsection{Abundance of aerosol components}

Analyses of AOD from the ECMWF MACC-II (Monitoring Atmospheric Composition and Climate - Interim Implementation) project are used by SIRAMix to characterize aerosol conditions with time and location. MACC-II follows the MACC and the GEMS (Global Monitoring for Environment and Security) initiatives started in 2006 to provide data on atmospheric composition for recent years, present conditions and forecasts for a few days ahead. MACC-II is based on a combination of information from models and assimilated remotely sensed aerosol observations from MODIS (Morcrette et al., 2009; Benedetti et al., 2009). Near real time AOD estimates are provided for 11 natural and anthropogenic aerosol components, in particular, hydrophilic and hydrophobic organic matter (OM), hydrophilic and hydrophobic black carbon (BC), sulfates (SU), three bins of sea salt (SS), and three bins of dust (DU). Each bin considers a different average particle size. Individual AOD estimates are made available in near real time at $550 \mathrm{~nm}$, every $3 \mathrm{~h}$, and at spatial resolution of $1.125^{\circ}$ through the forecast version of MACC-II data. Also, reanalyzed MACC-II data are released in delayed mode by the ECMWF. For this study, we have downloaded AOD data corresponding to the five major aerosol species (i.e., OM, BC, SU, SS, and DU). In this case, the AOD corresponding to the class DU, for example, is the sum of the AOD corresponding to the three bins of dust aerosols. The same applies to OM, BC and SS. Both forecast (fnyp experiment) and reanalyzed (rean experiment) aerosol data from MACC-II were considered to test their suitability in the upcoming implementation of SIRAMix in the LSASAF project. MACC-II aerosol data have been assessed to be of good quality in general (Mangold et al., 2011; Bellouin et al., 2013) but with notable uncertainties in some cases. For example, Cesnulyte et al. (2014) quantified the bias of forecast MACC-II AOD estimates from the experiment named fdmj (a term used by the MACC-II team for a given re-analysis experiment) for a series of ground stations to be 0.02 on average but to range between -0.20 ( $26 \%$ of total AOD in the often polluted urban area of Xianghe) and 0.12 (36\% of total AOD in the dusty Solar Village in Saudi Arabia). To cover a full day of AOD values, Cesnulyte et al. (2014) took hourly forecast AOD from time steps 1 to $12 \mathrm{~h}$ from forecast base times 00:00 and 12:00 UTC.

In SIRAMix, MACC-II AOD values are used to set the abundance of each of the five GADS-based aerosol components. Before using this information, however, the set of five MACC-II AOD values must be processed following three steps (see Fig. 2 and Appendix B).

- Step 1: from MACC-II to GADS. The AOD values for each MACC-II component (OM, BC, SU, SS, and DU) are converted into five AOD values, one for each GADS-based component used in SIRAMix (INSO, WASO, SOOT, SSALL, and MIALL). Optical proper- ties from aerosol components in MACC-II are not easily available, thus justifying such approach. This correspondence is quite straightforward as both sets of aerosol components are highly compatible. For example, sulfate particles from MACC-II (component SU) can be represented by the optical properties of water soluble aerosols in GADS (component WASO). More details on this AOD conversion and the GADS data base are found in Appendix B1.

- Step 2: height correction. MACC-II products are computed according to the average elevation of the spatial grid of $1.125^{\circ}$ (approximately $112.5 \mathrm{~km}$ at the equator) used by the ECMWF IFS. The height of a given ground station may not be the same than the altitude considered in the corresponding MACC-II grid pixel. Since aerosols are not homogeneously distributed along the vertical, AOD values analyzed by MACC-II may not be adequate to be used directly in SIRAMix. In order to overcome this issue, SIRAMix adjusts the MACC-II AOD estimates to the station actual height. More details on this height correction are found in Appendix B2. The resulting set of five height-corrected AOD values are used to evaluate the aerosol LUT to get the individual transmittances and albedo of each aerosol component in SIRAMix (see Fig. 2).

- Step 3: spectral conversion. The set of five AOD values are transformed from $550 \mathrm{~nm}$ to the shortwave spectral range to provide the weights needed to calculate the transmittances and the albedo of the aerosol layer following the approach described in Sect. 2.2.2 (see Fig. 2). More details on this spectral transformation are found in Appendix B3.

\subsection{Determination of clear sky moments}

The determination of clear sky conditions is fundamental for SIRAMix, which can only process cloud-free instants of time (i.e., atmosphere composed of aerosols and gases). SIRAMix selects clear-sky instants based upon the cloud mask provided by the NWC-SAF (http://www.nwcsaf.org/), which is built and released every 15 minutes from MSG infrared observations using the method from Derrien and Le Gléau (2005). Only instants of time flagged as "cloud free" in the NWC-SAF cloud mask are suitable to be processed by SIRAMix. For extra precaution, the cloud mask is dilated in time, ruling out any "cloud free" instant of time if any of the two previous $(-30 \mathrm{~min})$ or two next $(+30 \mathrm{~min})$ time slots are flagged as "cloudy". This second step is aimed to avoid broken clouds. This strategy for detection of clear sky instants is highly efficient mostly due to the high quality of the NWCSAF cloud mask (Carrer et al., 2010a, 2012), which allows it to distinguish highly turbid situations (i.e., high AOD) from cloudy ones. 


\section{Experimental setup}

Several experiments are conducted in the present article to assess the performances of SIRAMix. The evaluation is based upon the comparison of the DSSF computed by SIRAMix under distinct configurations against radiative transfer simulations, other DSSF products, and ground measurements. This procedure is in agreement with most works' assessing methods for DSSF retrieval (Gueymard, 2003; Deneke et al., 2005; Yang et al., 2006; Psiloglou and Kambezidis, 2007; Geiger et al., 2008b; Mueller et al., 2009; Liang et al., 2013; Moreno et al., 2013; Yoshida et al., 2013). Furthermore, an evaluation based on DSSF inspection may be useful to quantify the potential inaccuracies affecting SIRAMix DSSF estimates, which will be taken into account when using these radiation products as forcing in surface, atmospheric and weather forecast models. Validation based on derived parameters such as the clearness index (e.g., Lefèvre et al., 2013) was not considered in this study due to the proportionality of this index to DSSF in addition to the abovementioned reasons.

\subsection{DSSF data sets}

Different data sets of DSSF and in situ observations are used for validation purposes.

\subsubsection{Simulated DSSF: the radiative transfer code libRadtran}

Highly accurate values of global, direct, and diffuse DSSF are simulated using the software libRadtran (Mayer and Kylling, 2005) (http://www.libradtran.org). libRadtran is able to calculate downwelling solar irradiance at any altitude with an accuracy that is comparable to other state-ofthe-art radiative transfer codes (van Weele et al., 2000). A broad range of atmospheric and geometric situations can be taken into account by libRadtran. For instance, simulations of irradiance can be run considering an aerosol layer made of one or multiple GADS aerosol components. Furthermore, libRadtran accounts for the hygroscopicity of each aerosol component to modulate simulated irradiances as a function of atmospheric water vapor content.

\subsubsection{Other clear sky DSSF products}

The DSSF values issued from SIRAMix are compared with two state-of-the-art DSSF products.

- The LSA-SAF product. The operational system in the LSA-SAF computes the instantaneous global DSSF over the MSG Earth's disk every $30 \mathrm{~min}$. The method for its retrieval (Geiger et al., 2008b) is based on a parameterization of the DSSF in a simplified planeparallel atmosphere with constant pressure. Under clear sky conditions, incoming solar radiation is considered to be scattered by aerosols and gas molecules and absorbed by water vapor, ozone, aerosols, and to a lesser extent, oxygen and carbon dioxide. Absorption by other gases (e.g., $\mathrm{CO}, \mathrm{N}_{2} \mathrm{O}$, and $\mathrm{CH}_{4}$ ) is neglected. Near real time information on gases is retrieved from the ECMWF (i.e., forecast analyses), except for oxygen and carbon dioxide, which are assigned to a constant abundance. Also, aerosol conditions are considered to be constant across the MSG Earth's disk, adopting a typical continental aerosol type and a surface visibility of $20 \mathrm{~km}$. According Vermote et al. (2005), this value of visibility corresponds to an aerosol optical thickness of 0.25 at $550 \mathrm{~nm}$, approximately. The NWC-SAF cloud mask is used for detection of clear sky instants and the LSASAF product of surface albedo is used to take multiple scattering into consideration. Experiments in (Geiger et al., 2008b) showed a standard deviation of the difference between estimates of global DSSF and ground measurements in the order of $40 \mathrm{~W} \mathrm{~m}^{-2}$ for instantaneous clear sky data. LSA-SAF products are generated in near real time and in periodical reanalyses.

- The McClear product. The recent McClear approach (Lefèvre et al., 2013) represents the state of the art in DSSF retrieval as it considers dynamic aerosol data to estimate direct and global DSSF under clear sky conditions. Based on a comprehensive LUT of pre-computed DSSF values, McClear uses analyses of aerosol properties and total column content of water vapor and ozone from the ECMWF (i.e., forecasts in the first place and reanalyses when they become available). In particular, MACC-II data are used to characterize the aerosol layer, which is set to the total AOD given by MACC-II and represented by the most appropriate aerosol type among 10 available models. According Lefèvre et al. (2013), the selection of the aerosol type in McClear may be inadequate when the true aerosol conditions do not correspond to any of the available aerosol types (e.g., in the occurrence of mixtures of aerosol types). Another difference of McClear with regard to SIRAMix is the use of the MODISderived surface albedo. Clear sky instants of time are detected by McClear in two steps. First, all instants related to ground measurements not satisfying the condition $E_{\mathrm{dif}} / E<0.3$ are ruled out. Then, a second filter avoids the presence of broken clouds by retaining only 180 -minute periods with at least $30 \%$ of 1 min measurements passing the first filter. Comparison of McClear DSSF estimates to measurements made at several ground stations showed a root mean squared error (RMSE) for global irradiance ranging from 20 to $36 \mathrm{~W} \mathrm{~m}^{-2}$ and an RMSE for direct irradiance between 33 to $64 \mathrm{~W} \mathrm{~m}^{-2}$. McClear products used in the present article were downloaded from http://www.soda-pro. com/free-web-services/radiation/mcclear, where $1 \mathrm{~min}$ 


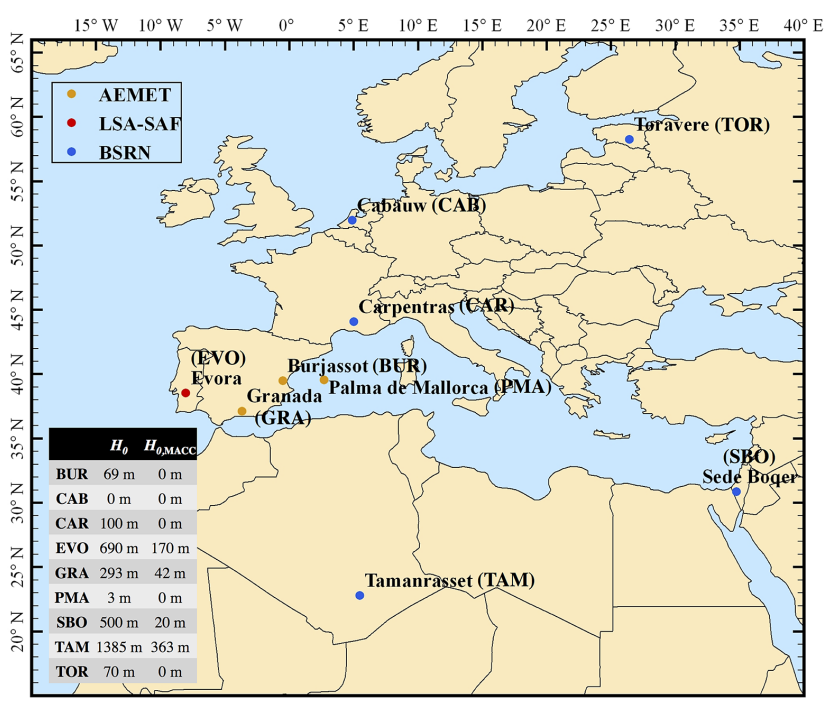

Figure 3. Map of ground stations used in this article. Different colors depict the different radiation networks. The height of each ground station $\left(H_{0}\right)$ and that of the corresponding pixel in the MACC-II grid ( $\left.H_{0, \mathrm{MACC}}\right)$ are given (see Sect. 2.3.3).

averaged DSSF estimates are available for all instants of time despite the cloud coverage (i.e., no clear sky filtering has been carried out).

\subsubsection{Ground DSSF measurements}

Accurate in situ measurements of instantaneous global, direct, and diffuse DSSF are used in this article for a selection of nine radiation stations across the MSG Earth's disk. Measurements are available for the 12 months of 2011. Figure 3 shows the location of the nine ground stations, which belong to different radiation networks and are representative of the broad variability of atmospheric conditions in the MSG Earth's disk. First, stations located in Cabauw, Carpentras, Sede Boqer, Tamanrasset, and Toravere belong to the Baseline Surface Radiation Network (BSRN) (http: //www.bsrn.awi.de/). BSRN stations provide measurements of global, direct, and diffuse solar radiation with instruments of high accuracy and time resolution. Similar measurements are carried out by stations in Burjassot, Granada, and Palma de Mallorca by the Spanish Weather Service (AEMET) (http: //www.aemet.es). Eventually, the ground station in Evora was set up within the validation activities of the LSA-SAF by the Karlsruhe Institute of Technology (KIT). For this station, only measurements of global DSSF are available.

\subsection{Description of experiments}

The objectives of the six experiments conducted in Sect. 4 are detailed as follows.
- Experiment 1 in Sect. 4.1.1 evaluates the accuracy of the DSSF estimated by SIRAMix against exact DSSF simulations from the radiative transfer code libRadtran.

- Experiment 2 in Sect. 4.1.2 investigates the sensitivity of SIRAMix regarding the quality of the inputs by quantifying the error of DSSF estimates when inputs are affected by inaccuracies.

- Experiment 3 in Sect. 4.1.3 shows the benefits of using a varying AOD as input of SIRAMix against the constant aerosol content assumed by the LSA-SAF product.

- Experiment 4 in Sect. 4.1.4 investigates the benefits of considering an aerosol layer made of a mixture of several aerosol species in SIRAMix against the fixed continental aerosol type adopted by the LSA-SAF product. DSSF observations from ground stations are used to evaluate the DSSF estimated by SIRAMix, on the one hand, and a reduced version of SIRAMix using a fixed continental aerosol type, on the other.

- Experiment 5 in Sect. 4.2 evaluates the accuracy of all estimates of global, direct, and diffuse DSSF provided by SIRAMix in 2011 for the nine ground stations shown in Fig. 3. In this experiment, SIRAMix DSSF estimates are compared against coincident in situ DSSF measurements and the LSA-SAF and McClear DSSF products.

- Experiment 6 in Sect. 4.3 investigates the capabilities of SIRAMix in quantifying the direct radiative forcing caused by aerosols and other atmospheric components. This feature of SIRAMix is made possible thanks to the accurate modeling of the downwelling atmospheric path done in the SIRAMix parameterization.

It is worth stressing here that all DSSF estimates or measurements considered in the experiments below are in units of $\mathrm{W} \mathrm{m}^{-2}$ and therefore instantaneous. This also applies to McClear 1-minute averaged estimates, as it can be considered that atmospheric conditions are invariant during $1 \mathrm{~min}$ (Lefèvre et al., 2013). Experiments 3-6 consider only the instantaneous DSSF values at 00 and $30 \mathrm{~min}$ for all DSSF data sets (i.e., SIRAMix, LSA-SAF, McClear and ground measurements). This choice is in agreement with the timeliness of the operational LSA-SAF DSSF product, which provides instantaneous DSSF every $30 \mathrm{~min}$ (corresponding to one MSG slot out of two). All DSSF data sets are then filtered to retain only clear sky instants of time using the filtering strategy defined in Sect. 2.4.

All experiments are conducted using reanalyzed MACCII aerosol data as input. Forecast analyses of AOD from MACC-II are also used in Experiment 5 to evaluate the performances of SIRAMix in an operational (near real time) configuration. The McClear DSSF product used in this article has been built based on MACC-II reanalyses. 

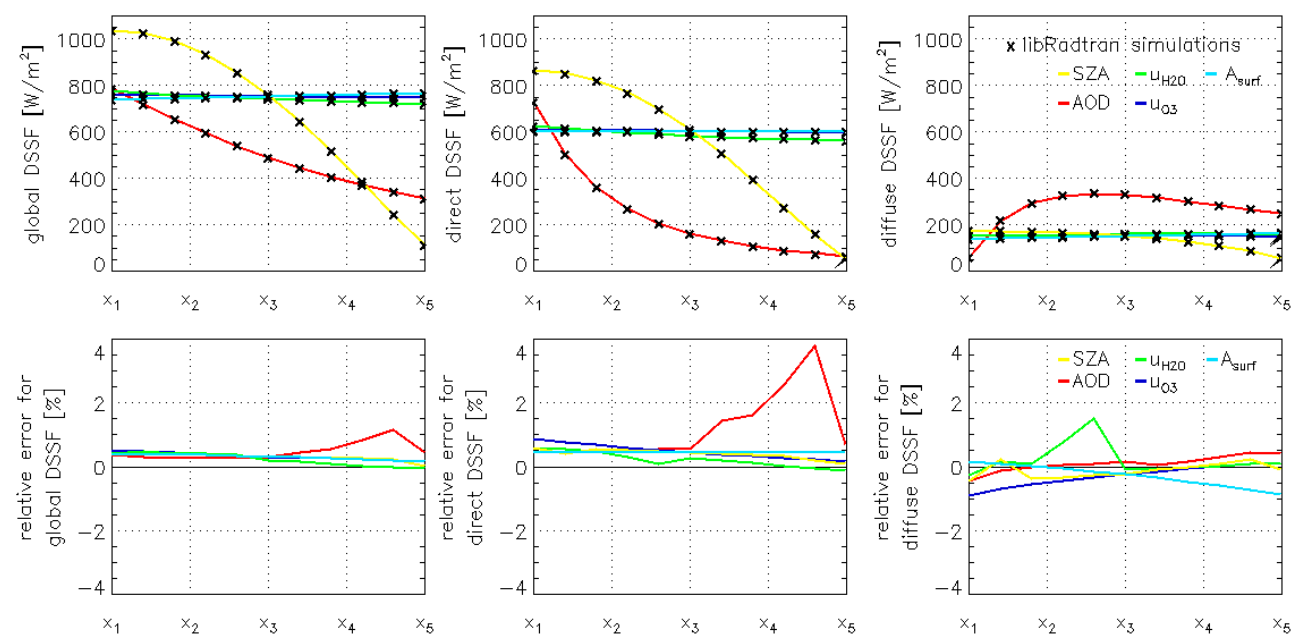

Figure 4. (top): global, direct, and diffuse DSSF values computed with SIRAMix according to varying AOD (red color), ozone content (dark blue color), water vapor concentration (green color), SZA (yellow color), and surface albedo (light blue color). Coincident DSSF simulations with libRadtran are shown with black crosses. (bottom): Relative error for global, direct, and diffuse DSSF values when compared to libRadtran simulations. Horizontal axis ticks $\left(x_{1}, x_{2}, x_{3}, x_{4}, x_{5}\right)$ correspond to $(0,1,2,3,4)$ for AOD, to $(0,125,250,375,500)$ in Dobson units for ozone, to $(0 ., 1.25,2.5,3.75,5.0)$ in $\mathrm{g} \mathrm{cm}^{-2}$ for water vapor, to $(0,20,40,60,80)$ in degrees for SZA, and to $(0.0,0.1,0.2,0.3,0.4)$ for surface albedo.

\section{Results}

\subsection{Performances of SIRAMix}

\subsubsection{Experiment 1: accuracy assessment of SIRAMix}

Figure 4 shows a comparison between the global, direct, and diffuse DSSF estimated by SIRAMix (solid lines) against exact DSSF simulations carried out by libRadtran (black crosses). Inputs in Table 3 are not used this time. In contrast, multiple atmospheric conditions are taken into account using different input values of SZA $\left(\theta_{0}\right)$ (yellow lines), AOD $\left(\delta_{0}\right)$ (red lines), ozone content $\left(u_{\mathrm{O}_{3}}\right)$ (dark blue lines), water vapor content $\left(u_{\mathrm{H}_{2} \mathrm{O}}\right)$ (green lines), and surface albedo ( $A_{\text {surf }}$ (light blue lines). Values of DSSF are shown in upper figures while relative errors appear in bottom figures. Standard conditions (i.e., $\theta_{0}=40^{\circ}, \delta_{0}=0.2, u_{\mathrm{O}_{3}}=300 \mathrm{DU}$, $u_{\mathrm{H}_{2} \mathrm{O}}=2.0 \mathrm{~g} \mathrm{~cm}^{-2}$, and $A_{\text {surf }}=0.2$ ) are considered for all DSSF calculations except for the parameter under study. The latter varies between 0 and 4 for AOD, 0 and $500 \mathrm{DU}$ for ozone, 0 and $5 \mathrm{~g} \mathrm{~cm}^{-2}$ for water vapor concentration, 0 and $80^{\circ}$ for SZA, and 0 and 0.4 for surface albedo.

As can be seen in Fig. 4, DSSF strongly depends on inputs of AOD and SZA. In contrast, the variations of water vapor, surface albedo and, especially, ozone content slightly modify the solar irradiance reaching the surface. Note that the increase of all parameters except for surface albedo and AOD results in a decrease of the direct and the diffuse DSSF components. In contrast, a large presence of aerosols infers an augmentation of the diffuse DSSF due to enhanced atmospheric scattering (and thus a decrease of direct radiation). Also, a highly reflective surface increases the multiple scat- tering between the surface and the lower layers of the atmosphere, thus increasing the amount of diffuse DSSF reaching the ground. In overall terms, global, direct, and diffuse DSSF values estimated by SIRAMix are in high agreement with coincident radiative transfer simulations. The relative error between both data sets remains below $1 \%$ in most of cases. The few errors beyond $1 \%$ come from numerical inaccuracies during the LUT interpolation. Note, for example, the greater relative error for direct DSSF when AOD is greater than 3 and for diffuse DSSF when water vapor is equal to $2.5 \mathrm{~g} \mathrm{~cm}^{-2}$. It is worth noticing that the absolute bias corresponding to the previous two examples barely goes beyond $3 \mathrm{~W} \mathrm{~m}^{-2}$, as DSSF is very low in this case.

The computational efficiency of SIRAMix is emphasized in this experiment, as the computational burden was reduced by more than a factor of 150 when calculating the series of DSSF values with SIRAMix $(0.1 \mathrm{~s}$ of total CPU time in a regular computer) instead of libRadtran (total CPU time of $18.8 \mathrm{~s})$.

\subsubsection{Experiment 2: sensitivity of SIRAMix to the input parameters}

The sensitivity of the proposed method SIRAMix to inaccurate atmospheric inputs is now investigated. Figure 5 shows the relative error affecting each DSSF component when two typical values of AOD (first-line figures), ozone concentration (second-line figures), water vapor amount (third-line figures), and surface albedo (fourth-line figures) are used as inputs and are manually biased from -25 to $25 \%$. Solid and dashed lines are respectively used for low and high concentrations of aerosol $\left(\delta_{0}=0.2\right.$ and $\left.\delta_{0}=1.0\right)$, 

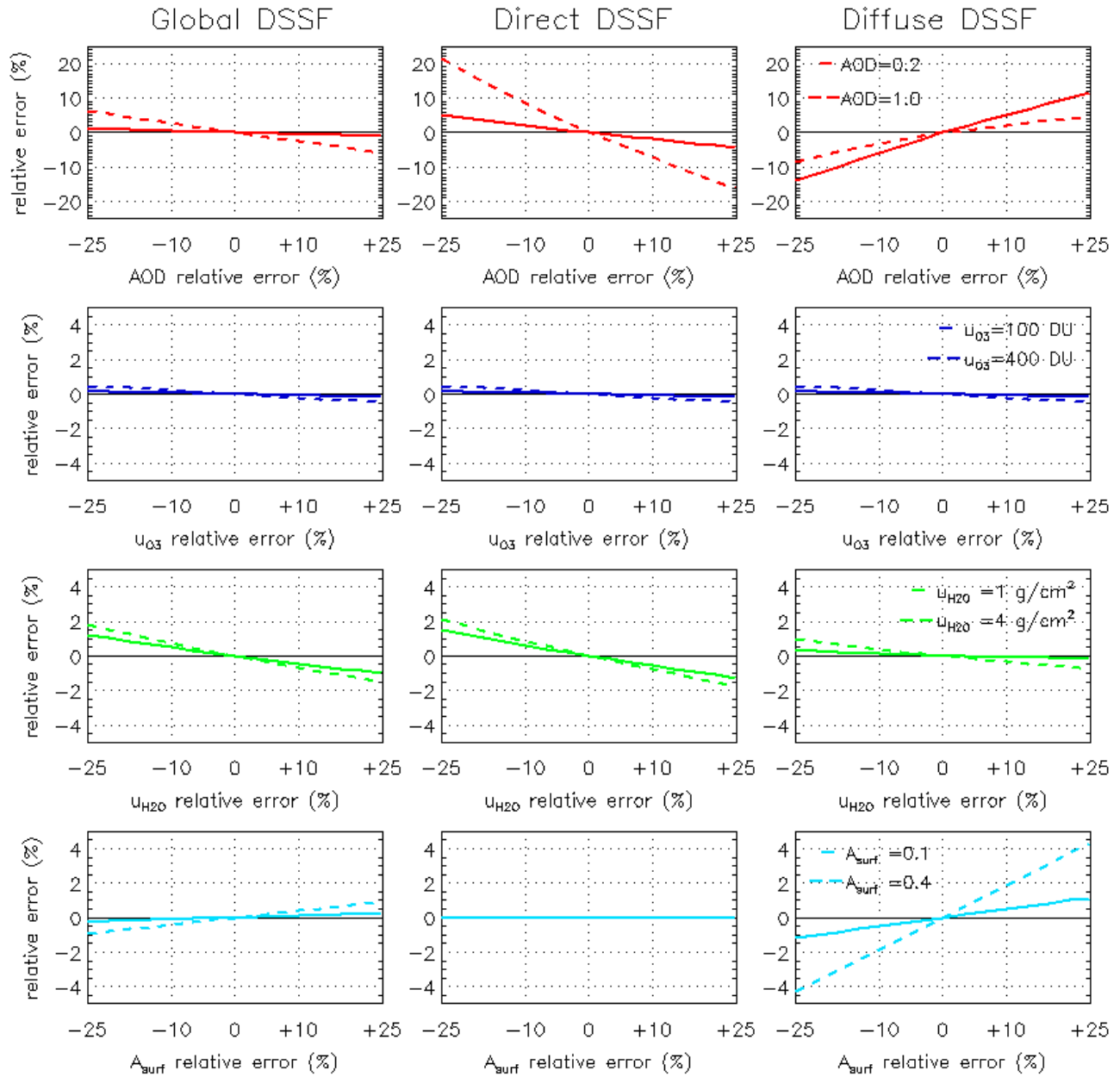

Figure 5. Relative error on global, direct, and diffuse DSSF computed with SIRAMix caused by uncertainties in terms of relative error affecting AOD (first-line figures), ozone content (second-line figures), water vapor concentration (third-line figures), and surface albedo (fourth-line figures). Two cases corresponding to different contents of the atmospheric component under study are studied (see plain and dashed lines). Note the different vertical scale for the study on the AOD.

water vapor $\left(u_{\mathrm{H}_{2} \mathrm{O}}=1.0 \mathrm{~g} \mathrm{~cm}^{-2}\right.$ and $\left.u_{\mathrm{H}_{2} \mathrm{O}}=4.0 \mathrm{~g} \mathrm{~cm}^{-2}\right)$, ozone $\left(u_{\mathrm{O}_{3}}=100 \mathrm{DU}\right.$ and $\left.u_{\mathrm{O}_{3}}=400 \mathrm{DU}\right)$, and surface albedo $\left(A_{\text {surf }}=0.1\right.$ and $\left.A_{\text {surf }}=0.4\right)$. Standard conditions (i.e., $\theta_{0}=40^{\circ}, \delta_{0}=0.2, u_{\mathrm{O}_{3}}=300 \mathrm{DU}, u_{\mathrm{H}_{2} \mathrm{O}}=2.0 \mathrm{~g} \mathrm{~cm}^{-2}$, and $A_{\text {surf }}=0.2$ ) are considered for all inputs other than the parameter under study.

According to Fig. 5, AOD uncertainty appears as the highest source of error on DSSF estimation (note the different vertical scale in this case). For example, a $-25 \%$ bias affecting an input AOD of 1.0 results in a relative error of $+21 \%$ for direct DSSF and $-9 \%$ for the diffuse term. In contrast, the error on global DSSF due to an inappropriate AOD value is generally lower (i.e., maximum global DSSF error of $+6 \%$ ), as errors coming from the direct and diffuse components compensate each other. On the other hand, inaccuracies on ozone content have a small impact on DSSF, not going beyond $0.5 \%$. Accuracy of water vapor estimates is of average importance, as it can induce errors of $2 \%$ on direct and global DSSF. Finally, experiments prove that the use of an inaccurate surface albedo may introduce moderate bias on diffuse DSSF when surfaces are bright $\left(A_{\text {surf }}=0.4\right)$. For example, the use of a surface albedo of 0.3 instead of $0.4(-25 \%$ bias $)$ results in the underestimation of the diffuse DSSF by $4 \%$ when AOD $=0.2$. This bias is expected to increase for higher aerosol loads.

\subsubsection{Experiment 3: benefits of considering a varying AOD}

Here, the impact on DSSF retrieval of considering an AOD that evolves with time is investigated. Figure 6 illustrates the performances of the proposed method SIRAMix and the current LSA-SAF approach during a 5-day period in July 2011 over the station of Sede Boqer (see Fig. 3). In this experiment, inputs in Table 3 are used to run SIRAMix. Ground measurements of global DSSF from the BSRN station in 

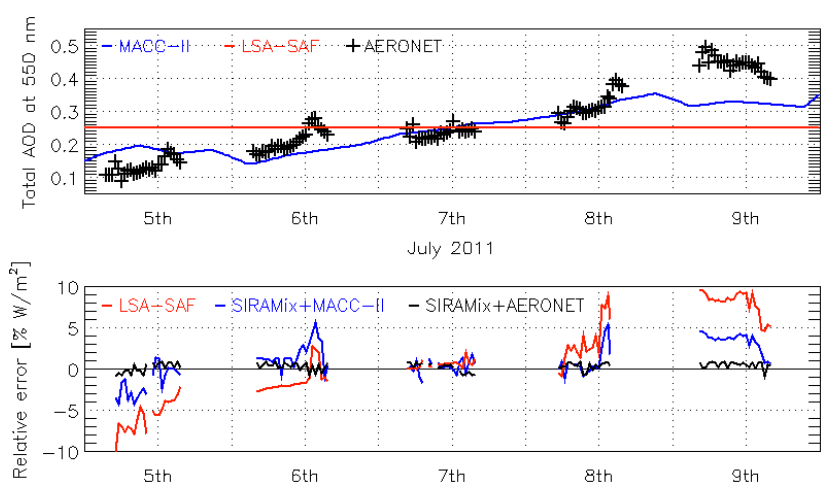

Figure 6. (top) evolution of the total AOD over Sede Boqer from the 5 to 9 July according to MACC-II and AERONET. The static AOD adopted by the LSA-SAF method is also shown. (bottom) Bias in $\mathrm{W} \mathrm{m}^{-2}$ between the estimated and in situ global DSSF from the BSRN station. DSSF is estimated using the LSA-SAF approach and the SIRAMix method using either MACC-II (i.e., SIRAMix+MACC-II) or AERONET (i.e., SIRAMix+AERONET) AOD inputs.

this location are used as validation data. As it can be seen in Fig. 6 (top), the aerosol load increased from $\delta_{0}=0.1$ to $\delta_{0}=0.5$ between the 5 and the 9 July, according to accurate in situ aerosol measurements from the AERONET (Aerosol Robotic Network) station in Sede Boqer (Holben et al., 1998). Note the acceptable precision of the AOD estimates provided by MACC-II during these dates. In contrast, the static $\operatorname{AOD}\left(\delta_{0}=0.25\right)$ adopted by the LSA-SAF product deviates significantly from the real aerosol conditions, while providing a good average value for the considered period of time. Figure 6 (bottom) shows that the use of a constant AOD to generate the LSA-SAF product results in a varying DSSF bias with time (see red line), which can reach $10 \%$. This is contrary to the highly accurate DSSF (up to $1 \%$ bias) computed with SIRAMix using AERONET measurements of total AOD (see black line). The generally good accuracy (up to $5 \%$ bias) of the global DSSF estimated by SIRAMix using MACC-II aerosol data (see blue line) underlines the benefits of considering a varying AOD with time. In this case, the impact of inaccuracies affecting MACC-II AOD data on the DSSF estimation is observed. In fact, the greatest bias affecting the SIRAMix DSSF happens on the 9th of July (relative error on global DSSF of $4 \%$ ) due to the underestimation of the MACC-II AOD product with regard to AERONET. Also, note the high correlation between the increase of DSSF bias during the evenings of 6 and 8 July with the AOD peaks seen in AERONET data (and absent in the MACC-II and LSASAF AOD data).

\subsubsection{Experiment 4: benefits of considering a mixture of aerosol components}

Two cases studies are defined in the present section to investigate the impact on the DSSF estimation of considering a mixture of several aerosol species. In the following, SIRAMix is normally run, that is, using the inputs in Table 3 and considering an aerosol layer made of five aerosol components evolving with time (see Sect. 2.2). In addition, a downgraded version of SIRAMix is run by considering an aerosol mixture made of a typical continental aerosol type (i.e., mixture made of component WASO mainly and, to a lesser extent, INSO and SOOT) (Hess et al., 1998). This second version of SIRAMix simulates the assumption of aerosol type made in the LSA-SAF product.

- Case study 1: first, SIRAMix is run in Cabauw (see Fig. 3) during all clear-sky instantaneous instants of time at 00 or $30 \mathrm{~min}$ of 2011. As it is seen in Fig. 7, sea salt aerosols are prevailing in this location during the winter months (see blue line), reaching $70 \%$ of the total AOD. In contrast, continental aerosols predominate during the rest of the year. Red bars in Fig. 7 show the variation of the monthly averages of instantaneous RMSE along 2011 if SIRAMix is run normally instead of using a fixed continental aerosol type. As it can be seen, there exists a high correlation between the predominance of sea salt aerosols (component SS) and the decrease of RMSE (up to $12 \mathrm{~W} \mathrm{~m}^{-2}$ ). In contrast, the performances of both configurations of SIRAMix are similar when continental aerosols are prevailing. Note that the RMSE averages in Fig. 7 are function of the quality of MACCII aerosol data, which can be different from reality as it was seen in Experiment 2 (see Sect. 4.1.2).

- Case study 2: the second case study investigates the transportation of dust aerosols to the station of Granada (see Fig. 3) from the Sahara desert during the summer months (Israelevich et al., 2012). Figure 8 illustrates the time period between the 24 and the 27 June 2011, when an aerosol dust plume reached southern Spain. As it can be seen, the amount of these mineral particles (component MI) increased from 30 to $80 \%$ of the total AOD during those days. On the other hand, the percentage of continental aerosols (components WASO, INSO, and SOOT) decreased from $65 \%$ to barely $20 \%$ of the total AOD. Figure 8 shows the benefits of taking into account this variation in the aerosol composition. In fact, the downgraded version of SIRAMix considering a fixed continental aerosol type results in RMSE values that are up to $10 \mathrm{~W} \mathrm{~m}^{-2}$ larger than when SIRAMix is normally run. 


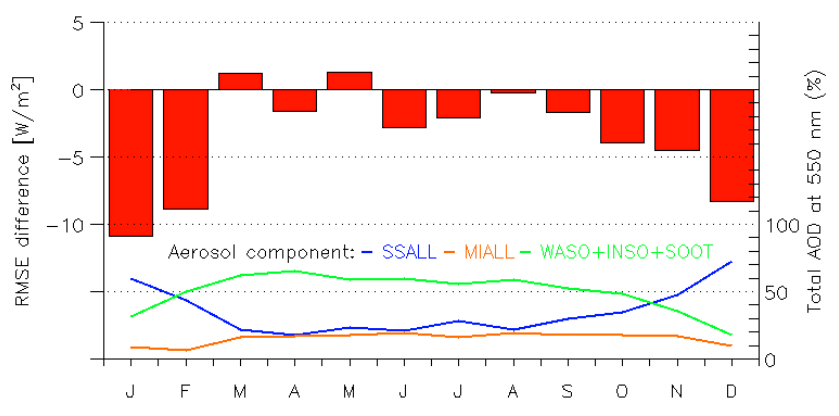

Figure 7. Left axis (red bars): monthly averaged RMSE difference in 2011 over Cabauw when SIRAMix is normally run (i.e., five-component aerosol layer) instead of using a fixed continental aerosol type. Negative values point out the error decrease when the aerosol mixture is considered. Right axis (color lines): abundance of aerosol components (see Sect. 2.2.1) in terms of percent of total AOD.

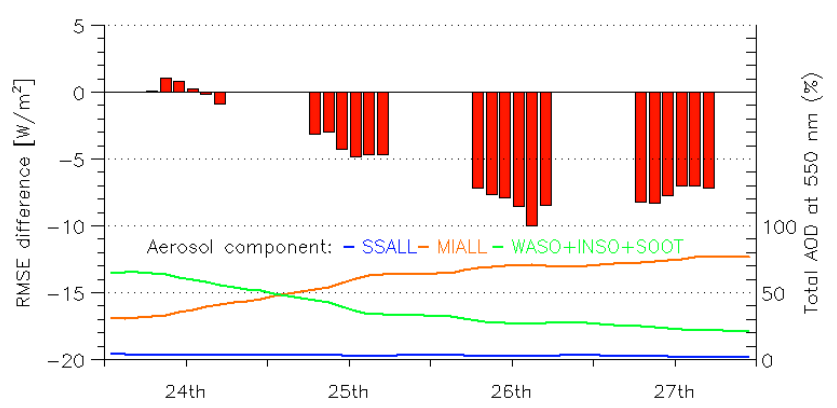

Figure 8. Left axis (red bars): $2 \mathrm{~h}$ averaged RMSE difference in Granada from the 24 to 27 June 2011 when SIRAMix is normally run (i.e., five-component aerosol layer) instead of using a fixed continental aerosol type. Negative values point out the error decrease when the aerosol mixture is considered. Right axis (color lines): abundance of aerosol components (see Sect. 2.2.1) in terms of percent of total AOD.

\subsection{Experiment 5: comparison of SIRAMix vs. other methods for DSSF retrieval}

In this experiment, the performances of SIRAMix are evaluated against ground measurements of DSSF. Estimates of global, direct, and diffuse DSSF are computed by SIRAMix every clear-sky instantaneous instant of time at 00 or $30 \mathrm{~min}$ in 2011 for the nine ground stations in Fig. 3. Coincident DSSF values are also made available from the state-of-the-art DSSF products LSA-SAF and McClear for comparison. Figure 9 shows the scatter plots between the three DSSF products (SIRAMix, McClear, and LSA-SAF) and the ground measurements. Also, Tables 4, 5, and 6 detail some statistical scores. It is worth recalling here that the LSA-SAF method only provides estimates of global DSSF. Also, MACC-II reanalyses were used for all experiments except for the case referred to as SIRAMix* (see Tables 4, 5, and 6) for which forecast MACC-II aerosol data were used. The outcomes of this experiment are detailed for the direct, diffuse, and global DSSF components in the following.

\subsubsection{Direct irradiance}

Table 4 and Fig. 9 (middle) show a similar accuracy in quantifying the direct DSSF for SIRAMix and McClear. The similar RMSE scores for most stations are mainly due to the strong dependency of direct DSSF on the total AOD, which comes from MACC-II for both SIRAMix and McClear. Differences among stations come from the diverse aerosol activity, which is quite mild for mid latitude locations such as Carpentras and Toravere (with an average RMSE of $30 \mathrm{~W} \mathrm{~m}^{-2}$, approximately) and rather extreme for dusty locations such as Tamanrasset and Sede Boqer (average RMSE of $70 \mathrm{~W} \mathrm{~m}^{-2}$, approximately). It is to be noted, however, that the quality of MACC-II AOD data is generally lower in the latter case (Cesnulyte et al., 2014). The observed negative bias (e.g., $-12.6 \mathrm{~W} \mathrm{~m}^{-2}$ for SIRAMix) may likely come from the overestimated aerosol load from MACC-II. Indeed, a lower AOD would result in a diminution of aerosol scattering that would increase the direct radiation reaching the ground. Eventually, a decrease of the SIRAMix performances are observed when using forecast aerosol data (e.g., average RMSE increase of $11.8 \mathrm{~W} \mathrm{~m}^{-2}$ when using forecast MACC-II data instead of reanalyses).

\subsubsection{Diffuse irradiance}

Table 5 and Fig. 9 (bottom) show a better accuracy of SIRAMix with regard to McClear in the estimation of the diffuse DSSF (average RMSE for all stations of $44.9 \mathrm{~W} \mathrm{~m}^{-2}$ for SIRAMix and $55.5 \mathrm{~W} \mathrm{~m}^{-2}$ for McClear). The improvement of the diffuse DSSF retrieval is manifest for many stations such as Burjassot, Granada, Sede Boqer, and Toravere (RMSE decrease due to SIRAMix with regard to McClear of $5.2,7.9,4.5$, and $6.4 \mathrm{~W} \mathrm{~m}^{-2}$, respectively). The most likely reason for this difference between SIRAMix and McClear is the strong dependence of diffuse DSSF on aerosol properties, which seem to be better reproduced by the five-component aerosol layer in SIRAMix. Again, the worse results obtained for Sede Boqer and Tamanrasset are due to an enhanced aerosol presence, which is not sufficiently well reproduced by MACC-II. The accuracy of SIRAMix suffers a decrease when using forecast MACC-II aerosol data instead of reanalyses (e.g., RMSE increase of $16.4 \mathrm{~W} \mathrm{~m}^{-2}$ ). Correlation coefficients must be here interpreted with precaution since the limited range of values for diffuse DSSF tends to decrease them without denoting poor performance. An evidence supporting this thesis is that in spite of the slightly higher individual correlation coefficients for McClear station by station (see Table 5), the average correlation is higher for SIRAMix $\left(R^{2}=0.67\right)$ than for McClear $\left(R^{2}=0.65\right)$.

The positive bias affecting all methods (e.g., $18.0 \mathrm{~W} \mathrm{~m}^{-2}$ for SIRAMix) may likely come from the overestimation of 

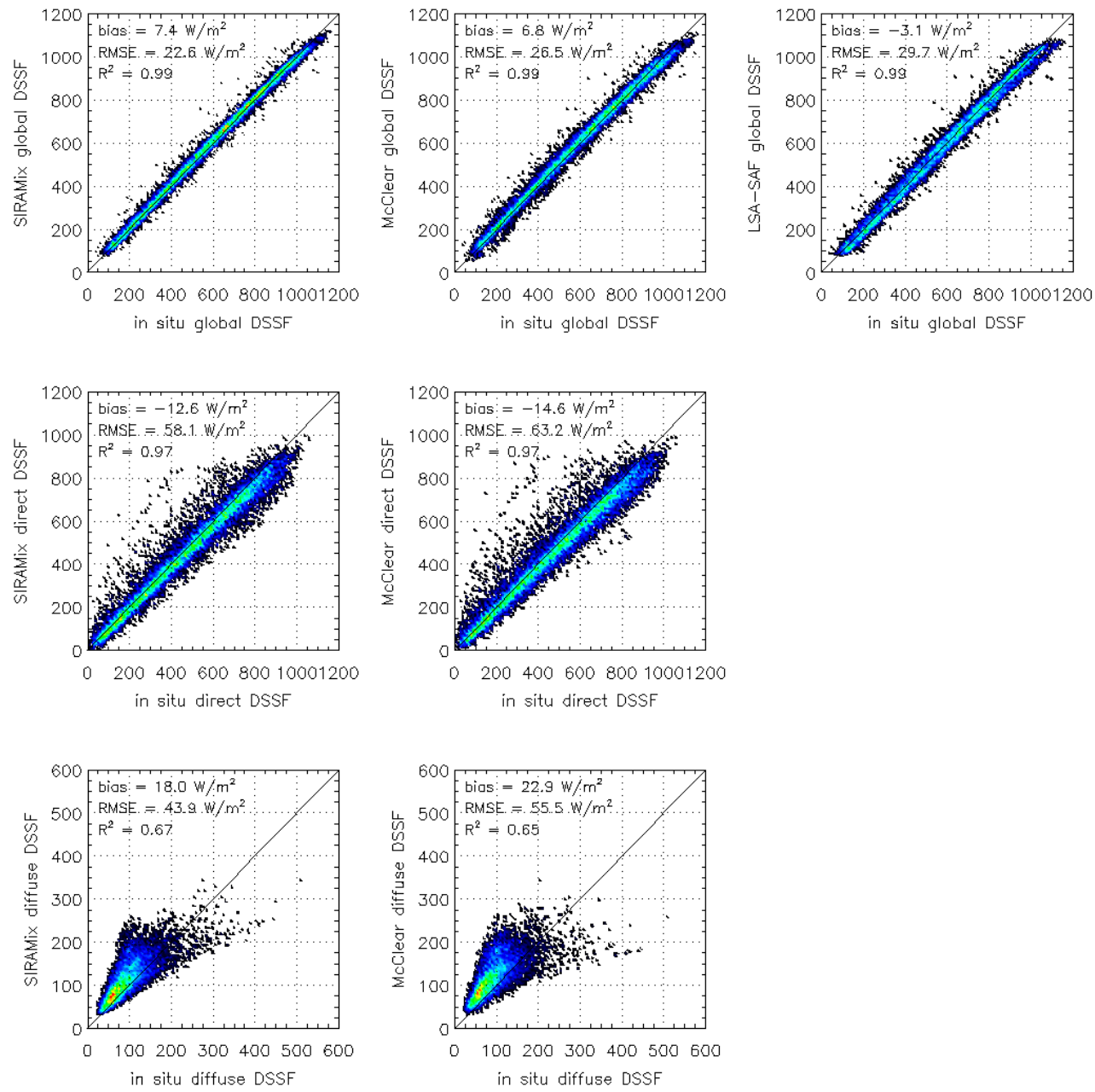

Figure 9. Scatter plots for global, direct, and diffuse DSSF obtained when the retrieval methods SIRAMix, McClear, and LSA-SAF are compared with coincident ground measurements.

the AOD by MACC-II. The consideration in SIRAMix of a too high aerosol load would result in an increase of the atmospheric scattering and therefore of the diffuse radiation. Despite the better estimation of diffuse DSSF by SIRAMix with regard to other methods, the mean RMSE represents a $41 \%$ of the average diffuse radiation (see Table 5). This is greater than for the direct DSSF, whose RMSE represents only the $12 \%$ of the average radiation (see Table 4 ). This difference is originated in the higher sensitivity of diffuse radiation to AOD inaccuracies under typical aerosol contents. This can be seen in Fig. 5, which shows a bias larger than $\pm 10 \%$ for diffuse DSSF when AOD is 0.2 and the associated bias is $\pm 25 \%$. Under the same configuration, direct DSSF suffers only from a bias not greater than $\pm 5 \%$. Also, the physical parameterization used in SIRAMix is probably less accurate for diffuse DSSF, as the modeling of this radiation component is more challenging than the direct one. Likewise, the aerosol look up table generated with libRadtran is likely less accurate in terms of diffuse transmittances due to the same reasons. Finally, the accuracy of measurements taken by ground stations is generally lower for diffuse radiation, as the measuring technique is more challenging in this case.

\subsubsection{Global DSSF}

Table 6 and Fig. 9 (top) show lower errors for global DSSF in comparison with the direct and diffuse components. This outcome is due to the lower sensitivity of global DSSF to the quality of aerosol information, as direct and diffuse errors compensate each other (see Fig. 5). The general positive bias (e.g., $7.4 \mathrm{~W} \mathrm{~m}^{-2}$ for SIRAMix) comes from the also positive bias affecting the diffuse DSSF (probably due to an overestimated AOD), which is greater in magnitude than the negative bias impacting direct DSSF. In general, global DSSF is more accurately retrieved by SIRAMix with regard to the other methods under study due to its better estimation of the diffuse DSSF. In particular, the average RMSE for 
Table 4. Accuracy scores for instantaneous values of direct DSSF estimated by SIRAMix for all clear-sky instantaneous instants of time at 00 or $30 \mathrm{~min}$ and the nine ground stations in 2011. Ground measurements are used as reference. Results from the LSA-SAF and McClear products are also shown for comparison. Measurements of direct DSSF are not available for stations in Evora and Granada. For this experiment, SIRAMix is also run using MACC-II aerosol forecasts instead of reanalyses. The forecast configuration is referred to as SIRAMix*.

\begin{tabular}{|c|c|c|c|c|c|c|}
\hline Station & $\begin{array}{l}\text { Retrieval } \\
\text { method }\end{array}$ & Number & $\begin{array}{l}\text { Average } \\
{\left[\mathrm{W} \mathrm{m}^{-2}\right]}\end{array}$ & $\begin{array}{r}\text { Bias } \\
{\left[\mathrm{W} \mathrm{m}^{-2}\right]}\end{array}$ & $\begin{array}{r}\text { RMSE } \\
{\left[\mathrm{W} \mathrm{m}^{-2}\right]}\end{array}$ & $R^{2}$ \\
\hline \multirow{2}{*}{ Burjassot } & SIRAMix & \multirow{2}{*}{1558} & \multirow{2}{*}{474.3} & 4.2 & 62.7 & 0.91 \\
\hline & McClear & & & 1.3 & 61.1 & 0.93 \\
\hline \multirow{2}{*}{ Cabauw } & SIRAMix & \multirow{2}{*}{861} & \multirow{2}{*}{333.1} & 2.4 & 34.9 & 0.95 \\
\hline & McClear & & & 2.9 & 38.0 & 0.95 \\
\hline \multirow{2}{*}{ Carpentras } & SIRAMix & \multirow{2}{*}{2494} & \multirow{2}{*}{465.3} & -9.3 & 32.8 & 0.98 \\
\hline & McClear & & & -11.0 & 33.6 & 0.98 \\
\hline \multirow{2}{*}{ Palma de Mallorca } & SIRAMix & \multirow{2}{*}{452} & \multirow{2}{*}{460.3} & -22.9 & 64.8 & 0.93 \\
\hline & McClear & & & -21.8 & 62.0 & 0.94 \\
\hline \multirow{2}{*}{ Sede Boqer } & SIRAMix & \multirow{2}{*}{3903} & \multirow{2}{*}{526.5} & -47.8 & 73.7 & 0.95 \\
\hline & McClear & & & -50.5 & 71.8 & 0.97 \\
\hline \multirow{2}{*}{ Tamanrasset } & SIRAMix & \multirow{2}{*}{3313} & \multirow{2}{*}{511.3} & 17.3 & 76.2 & 0.89 \\
\hline & McClear & & & 15.5 & 82.3 & 0.90 \\
\hline \multirow{2}{*}{ Toravere } & SIRAMix & \multirow{2}{*}{845} & \multirow{2}{*}{404.1} & -19.6 & 29.7 & 0.98 \\
\hline & McClear & & & -20.8 & 32.3 & 0.98 \\
\hline \multirow{3}{*}{ All } & SIRAMix & \multirow{3}{*}{13426} & \multirow{3}{*}{483.0} & -12.6 & 59.1 & 0.97 \\
\hline & SIRAMix* & & & -16.9 & 70.9 & 0.95 \\
\hline & McClear & & & -14.6 & 63.2 & 0.97 \\
\hline
\end{tabular}

all stations is $23.6,26.5$, and $29.7 \mathrm{~W} \mathrm{~m}^{-2}$ for SIRAMix with reanalyzed MACC-II aerosol data, McClear, and LSA-SAF, respectively. Table 6 shows the correlation between the improvement on DSSF estimation using SIRAMix and the stations with highly mixed aerosol conditions (see second column of Table 6 and stations in Burjassot, Granada, and Sede Boqer). This improvement comes from the consideration in SIRAMix of a mixed aerosol layer instead of a single aerosol type, as it is done in the LSA-SAF and McClear products. Although the LSA-SAF product provides acceptable scores in terms of average bias, the average RMSE is significantly higher than for SIRAMix due to the consideration of static aerosol conditions. Given that RMSE (lower for SIRAMix) is a quadratic combination of the bias (quite similar for all methods) and the standard deviation, the latter score also remains lower for SIRAMix with regard to the other methods (not shown). Eventually, it is interesting to observe that the implementation of SIRAMix with forecast MACC-II aerosol data provides similar scores to those obtained by the current LSA-SAF product.

\subsection{Experiment 6: towards new surface products to monitor atmospheric direct radiative forcing}

The parameterization of the downwelling atmospheric path at the core of SIRAMix provides the means to quantify the

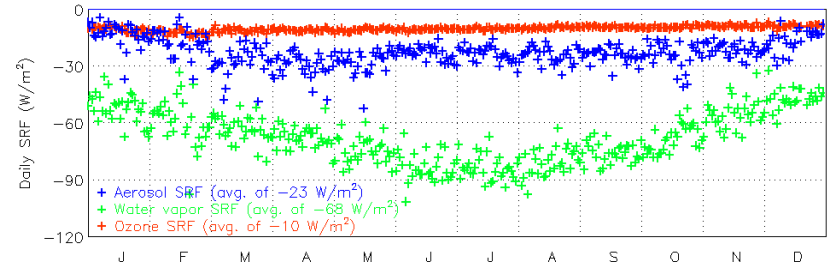

Figure 10. Daily surface radiative forcing due to aerosols (blue), water vapor (green), and ozone (red) in 2011 resulting from averaging over the nine ground stations considered in this study.

direct radiative forcing at the surface (SRF) caused by a given atmospheric component. The surface radiative forcing $(\Delta E)$ due to a given atmospheric component is defined as the difference, in $\mathrm{W} \mathrm{m}^{-2}$, between the net solar irradiance at the surface $\left(E_{\text {net }}\right)$ and the same quantity when the atmospheric component under study is absent $\left(E_{\text {net }}^{*}\right)$

$\Delta E=E_{\text {net }}-E_{\text {net }}^{*}$,

where the net irradiance is the difference between the DSSF ( $E$ or $E^{\downarrow}$ here, for the sake of clarity) and the upwelling flux $\left(E^{\uparrow}\right)$

$E_{\text {net }}=E^{\downarrow}-E^{\uparrow}$, 
Table 5. Idem to Table 4 for diffuse irradiance. Measurements of diffuse DSSF are not available for the station in Evora.

\begin{tabular}{|c|c|c|c|c|c|c|}
\hline Station & $\begin{array}{l}\text { Retrieval } \\
\text { method }\end{array}$ & Number & $\begin{array}{l}\text { Average } \\
{\left[\mathrm{W} \mathrm{m}^{-2}\right]}\end{array}$ & $\begin{array}{r}\text { Bias } \\
{\left[\mathrm{W} \mathrm{m}^{-2}\right]}\end{array}$ & $\begin{array}{r}\text { RMSE } \\
{\left[\mathrm{W} \mathrm{m}^{-2}\right]}\end{array}$ & $R^{2}$ \\
\hline \multirow{2}{*}{ Burjassot } & SIRAMix & \multirow{2}{*}{1558} & \multirow{2}{*}{121.4} & -8.7 & 36.3 & 0.48 \\
\hline & McClear & & & 6.3 & 41.5 & 0.52 \\
\hline \multirow{2}{*}{ Cabauw } & SIRAMix & \multirow{2}{*}{861} & \multirow{2}{*}{112.4} & -1.4 & 25.0 & 0.67 \\
\hline & McClear & & & 5.4 & 29.7 & 0.61 \\
\hline \multirow{2}{*}{ Carpentras } & SIRAMix & \multirow{2}{*}{2494} & \multirow{2}{*}{87.7} & 15.7 & 28.0 & 0.53 \\
\hline & McClear & & & 23.9 & 34.0 & 0.59 \\
\hline \multirow{2}{*}{ Granada } & SIRAMix & \multirow{2}{*}{2316} & \multirow{2}{*}{91.0} & 5.1 & 23.4 & 0.60 \\
\hline & McClear & & & 21.2 & 31.3 & 0.72 \\
\hline \multirow{2}{*}{ Palma de Mallorca } & SIRAMix & \multirow{2}{*}{452} & \multirow{2}{*}{107.0} & 25.5 & 43.9 & 0.42 \\
\hline & McClear & & & 31.2 & 43.0 & 0.49 \\
\hline \multirow{2}{*}{ Sede Boqer } & SIRAMix & \multirow{2}{*}{3903} & \multirow{2}{*}{109.0} & 59.8 & 65.0 & 0.49 \\
\hline & McClear & & & 58.7 & 69.5 & 0.55 \\
\hline \multirow{2}{*}{ Tamanrasset } & SIRAMix & \multirow{2}{*}{3313} & \multirow{2}{*}{138.6} & -4.1 & 62.0 & 0.61 \\
\hline & McClear & & & -7.6 & 68.5 & 0.68 \\
\hline \multirow{2}{*}{ Toravere } & SIRAMix & \multirow{2}{*}{845} & \multirow{2}{*}{80.2} & 18.4 & 25.1 & 0.71 \\
\hline & McClear & & & 23.2 & 31.5 & 0.56 \\
\hline \multirow{3}{*}{ All } & SIRAMix & \multirow{3}{*}{15742} & \multirow{3}{*}{109.0} & 18.0 & 44.9 & 0.67 \\
\hline & SIRAMix* & & & 24.8 & 61.3 & 0.59 \\
\hline & McClear & & & 22.9 & 55.5 & 0.65 \\
\hline
\end{tabular}

and can be expressed as a function of the surface albedo

$E_{\text {net }}=\left(1-A_{\text {surf }}\right) E^{\downarrow}$

making eventually

$\Delta E=\left(1-A_{\text {surf }}\right)\left(E^{\downarrow}-E^{\downarrow *}\right)$.

The instantaneous SRF due to a given atmospheric component can be easily quantified by SIRAMix using the estimated DSSF $\left(E^{\downarrow}\right)$ and the corresponding surface albedo into Eq. (27). Quantity $E^{\downarrow *}$ is computed considering a null abundance for the atmospheric quantity under study (e.g., SRF due to water vapor is computed setting $u_{\mathrm{H}_{2} \mathrm{O}}=0$ ).

Figure 10 shows the temporal evolution of the daily SRF due to aerosols, water vapor, and ozone along 2011 as computed by SIRAMix. Only clear sky instants of time were considered. Each value (represented as a colored cross) results from the averaging of the daily $\Delta E$ corresponding to the nine stations under study (see Fig. 3). As it can be seen, the presence of water vapor in the atmosphere results in the highest $\mathrm{SRF}$, with an average of $-68 \mathrm{~W} \mathrm{~m}^{-2}$. Water vapor forcing becomes greater in the summer months when air humidity is at its maximum in the Northern Hemisphere (where the ground stations are located, see Fig. 3). In opposite, atmospheric ozone weakly impacts the net flux balance at the surface and the SRF is only $-10 \mathrm{~W} \mathrm{~m}^{-2}$ in average. Eventually, aerosols result in a highly varying SRF due to the rapid evolution of AOD in time and space. The SRF due to aerosols is $-23 \mathrm{~W} \mathrm{~m}^{-2}$ in average, ranging between $-5 \mathrm{~W} \mathrm{~m}^{-2}$ for clear conditions and $-53 \mathrm{~W} \mathrm{~m}^{-2}$ for highly turbid situations.

The aerosol direct forcing obtained by SIRAMix is in agreement with the values found in the literature for several regions of the world. For example, Péré et al. (2011) determined the mean aerosol SRF over the Mediterranean Basin in August 2003 to range from -10 to $-30 \mathrm{~W} \mathrm{~m}^{-2}$ using a chemistry-transport model coupled with a meteorological model. On the other hand, ground measurements of DSSF allowed di Sarra et al. (2013) to quantify the average aerosol SRF on September 2005 as $-24 \mathrm{~W} \mathrm{~m}^{-2}$ in the Mediterranean station of Lampedusa. A similar average was obtained by the MILAGRO (Megacity Initiative-Local and Global Research Observations) campaign in March 2006 over Mexico (Schmidt et al., 2010), which resulted in an average aerosol $\mathrm{SRF}$ of $-22 \mathrm{~W} \mathrm{~m}^{-2}$. Likewise, Bush and Valero (2003) quantified the aerosol SRF over a mid-latitude region such as South Korea to be between -11 and $-52 \mathrm{~W} \mathrm{~m}^{-2}$ (average of $30 \mathrm{~W} \mathrm{~m}^{-2}$ ). Finally, Mallet et al. (2006) and Roger et al. (2006) used measurements of microphysical and optical aerosol properties obtained during the ESCOMPTE (ExperimentS to COnstrain Models of atmospheric Pollution and Transport of Emissions) campaign to simulate average values 
Table 6. Idem to Table 4 for global irradiance. Second columns details the percentage in total AOD of the two most abundant aerosol components for each station. In this way, stations with homogeneous aerosol conditions (e.g., Tamanrasset) can be distinguished from heterogeneous ones (e.g., Granada).

\begin{tabular}{|c|c|c|c|c|c|c|c|}
\hline Station & $\begin{array}{l}\% \text { of the two } \\
\text { predominant } \\
\text { GADS comp. }\end{array}$ & $\begin{array}{l}\text { DSSF } \\
\text { retrieval } \\
\text { method }\end{array}$ & Number & $\begin{array}{r}\text { Average } \\
\text { DSSF } \\
{\left[\mathrm{W} \mathrm{m}^{-2}\right]}\end{array}$ & $\begin{array}{r}\text { Average } \\
\text { Bias } \\
{\left[\mathrm{W} \mathrm{m}^{-2}\right]}\end{array}$ & $\begin{array}{r}\text { Average } \\
\text { RMSE } \\
{\left[\mathrm{W} \mathrm{m}^{-2}\right]}\end{array}$ & $\mathrm{R}^{2}$ \\
\hline Burjassot & $51 \%, 32 \%$ & $\begin{array}{l}\text { SIRAMix } \\
\text { LSA-SAF } \\
\text { McClear }\end{array}$ & 1558 & 595.7 & $\begin{array}{r}7.6 \\
-3.2 \\
7.6\end{array}$ & $\begin{array}{l}35.6 \\
41.6 \\
38.0\end{array}$ & $\begin{array}{l}0.98 \\
0.97 \\
0.98\end{array}$ \\
\hline Cabauw & $66 \%, 14 \%$ & $\begin{array}{l}\text { SIRAMix } \\
\text { LSA-SAF } \\
\text { McClear }\end{array}$ & 861 & 445.5 & $\begin{array}{r}-2.0 \\
-2.0 \\
8.3\end{array}$ & $\begin{array}{l}19.0 \\
24.4 \\
23.0\end{array}$ & $\begin{array}{l}0.99 \\
0.99 \\
0.99\end{array}$ \\
\hline Carpentras & $57 \%, 13 \%$ & $\begin{array}{l}\text { SIRAMix } \\
\text { LSA-SAF } \\
\text { McClear }\end{array}$ & 2494 & 552.9 & $\begin{array}{r}7.1 \\
-2.9 \\
12.9\end{array}$ & $\begin{array}{l}17.3 \\
18.2 \\
21.6\end{array}$ & $\begin{array}{l}1.00 \\
1.00 \\
0.99\end{array}$ \\
\hline Granada & $37 \%, 39 \%$ & $\begin{array}{l}\text { SIRAMix } \\
\text { LSA-SAF } \\
\text { McClear }\end{array}$ & 2316 & 592.3 & $\begin{array}{r}6.2 \\
-17.1 \\
2.9\end{array}$ & $\begin{array}{l}20.5 \\
32.5 \\
26.9\end{array}$ & $\begin{array}{l}0.99 \\
0.99 \\
0.98\end{array}$ \\
\hline Evora & $67 \%, 16 \%$ & $\begin{array}{l}\text { SIRAMix } \\
\text { LSA-SAF } \\
\text { McClear }\end{array}$ & 1966 & 610.7 & $\begin{array}{r}2.8 \\
-6.2 \\
3.4\end{array}$ & $\begin{array}{l}34.4 \\
38.3 \\
35.9\end{array}$ & $\begin{array}{l}0.98 \\
0.98 \\
0.98\end{array}$ \\
\hline Palma de Mallorca & $53 \%, 17 \%$ & $\begin{array}{l}\text { SIRAMix } \\
\text { LSA-SAF } \\
\text { McClear }\end{array}$ & 452 & 567.2 & $\begin{array}{r}-8.1 \\
-5.3 \\
9.3\end{array}$ & $\begin{array}{l}33.5 \\
30.3 \\
34.3\end{array}$ & $\begin{array}{l}0.99 \\
0.99 \\
0.98\end{array}$ \\
\hline Sede Boqer & $46 \%, 34 \%$ & $\begin{array}{l}\text { SIRAMix } \\
\text { LSA-SAF } \\
\text { McClear }\end{array}$ & 3903 & 635.6 & $\begin{array}{r}15.0 \\
20.9 \\
8.7\end{array}$ & $\begin{array}{l}26.9 \\
39.8 \\
29.7\end{array}$ & $\begin{array}{l}0.99 \\
0.99 \\
0.99\end{array}$ \\
\hline Tamanrasset & $82 \%, 11 \%$ & $\begin{array}{l}\text { SIRAMix } \\
\text { LSA-SAF } \\
\text { McClear }\end{array}$ & 3313 & 649.9 & $\begin{array}{r}9.2 \\
-18.0 \\
4.9\end{array}$ & $\begin{array}{l}27.9 \\
35.0 \\
28.2\end{array}$ & $\begin{array}{l}0.99 \\
0.99 \\
0.99\end{array}$ \\
\hline Toravere & $63 \%, 21 \%$ & $\begin{array}{l}\text { SIRAMix } \\
\text { LSA-SAF } \\
\text { McClear }\end{array}$ & 845 & 484.4 & $\begin{array}{r}-1.3 \\
-10.8 \\
2.4\end{array}$ & $\begin{array}{l}15.4 \\
21.5 \\
18.5\end{array}$ & $\begin{array}{l}0.99 \\
0.99 \\
0.99\end{array}$ \\
\hline All & $58 \%, 23 \%$ & $\begin{array}{l}\text { SIRAMix } \\
\text { SIRAMix* } \\
\text { LSA-SAF } \\
\text { McClear }\end{array}$ & 17708 & 596.5 & $\begin{array}{r}7.4 \\
6.9 \\
-3.1 \\
6.8\end{array}$ & $\begin{array}{l}23.6 \\
29.1 \\
29.7 \\
26.5\end{array}$ & $\begin{array}{l}0.99 \\
0.99 \\
0.99 \\
0.99\end{array}$ \\
\hline
\end{tabular}

of aerosol SRF equal to $-(24-47) \mathrm{W} \mathrm{m}^{-2}$ for the southeast of France in June-July 2001.

The proposed method SIRAMix can go further by estimating the SRF due to each aerosol type. Figure 11 shows the distribution of the average aerosol SRF in 2011 due to each one of the five aerosol components considered in SIRAMix for stations in Cabauw, Carpentras, Granada, and Tamanrasset. As it can be seen, components WASO and MIALL are the aerosol species resulting in the largest SRF values due to the predominance of these particles in the atmosphere (up to $-12.4 \mathrm{~W} \mathrm{~m}^{-2}$ for WASO and $-19.1 \mathrm{~W} \mathrm{~m}^{-2}$ for MIALL). Note the increasing importance of desert dust aerosols ac- cording to latitude, going from $25 \%$ of the total aerosol SRF in Cabauw $\left(-7.6 \mathrm{~W} \mathrm{~m}^{-2}\right)$ to more than $90 \%$ in Tamanrasset $\left(-19.1 \mathrm{~W} \mathrm{~m}^{-2}\right)$. Also, the presence of component SSALL reaches its highest SRF in Cabauw $\left(-4.8 \mathrm{~W} \mathrm{~m}^{-2}\right)$ due to the presence of sea salt aerosols during the winter months (see case study 2 in Experiment 4).

\section{Discussion}

Experiments in the previous section have shown the good performances of SIRAMix to provide accurate estimates of global, direct, and diffuse DSSF. Thanks to the use of 

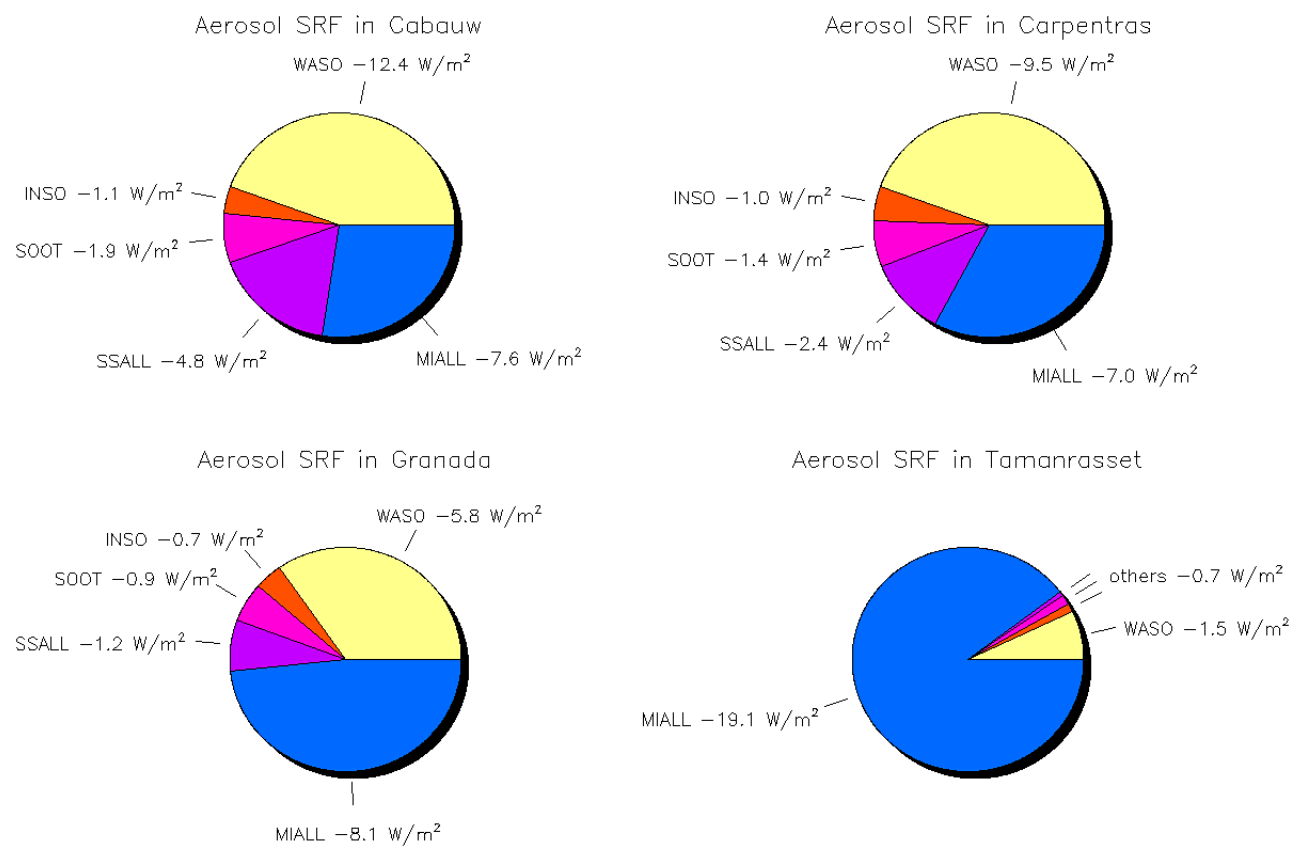

Figure 11. Circle graphs showing the average surface radiative forcing (SFR) in 2011 due to each aerosol component considered in SIRAMix for a selected set of stations.

dynamic aerosol information, a significant improvement in terms of RMSE is observed in the estimation of global DSSF in comparison with the LSA-SAF product. This is the case of stations related to short-term changing aerosol conditions, for which the static AOD adopted by the LSA-SAF algorithm fails to reproduce the DSSF evolution (see Experiment 3). However, the LSA-SAF product may become comparable to SIRAMix for stations where average aerosol conditions are close to those adopted by the LSA-SAF (e.g., see results for Carpentras in Experiment 5). This is in agreement with Ineichen et al. (2009), who found that the global DSSF produced by the LSA-SAF had a similar quality than other products considering more realistic aerosol information. However, the use of realistic aerosol data, as it is done for SIRAMix, is mandatory to split global DSSF into the direct and diffuse terms.

A novelty of SIRAMix with regard to other state-of-the-art methods is the consideration of a dynamic aerosol mixture. In this case, the total AOD produced by MACC-II is exploited along with the mixing ratios of the different aerosol components. The consideration of several species allows SIRAMix to improve the estimation of the global DSSF and, in particular, the diffuse DSSF (see Experiments 4 and 5). In fact, the latter radiative quantity is very sensitive to the aerosol extinction properties, and thus, the aerosol composition (Ceamanos et al., 2014). This asset of SIRAMix is particularly remarkable when aerosol conditions are quite heterogeneous, with several predominant aerosol species (see results for Granada in Experiment 5). Contrary to SIRAMix, the state-of-the-art McClear algorithm shows some limitations in this regard, as it chooses a single aerosol type for each DSSF retrieval. This outcome is in agreement with several studies (Wang and Martin, 2007; Behnert et al., 2007) stating that default aerosol types are often not representative of real aerosol conditions. Note that SIRAMix is able to consider other aerosol components than the five GADS-based species used in this article.

Another reason explaining the differences between the diffuse DSSF estimated by SIRAMix and McClear might be the use of different surface albedo products. The differences between the LSA-SAF MSG-derived albedo used in SIRAMix and the MODIS-derived one in McClear may contribute to the obtention of distinct diffuse DSSF estimates. Indeed, diffuse DSSF depends on surface albedo, as it determines the multiple scattering between the surface and the lower layers of the atmosphere (see Sect. 4.1.1). Nonetheless, the better estimation of diffuse DSSF by SIRAMix cannot be explained only by the use the LSA-SAF surface albedo, as this would mean that this product is generally more accurate than MODIS's (see Sect. 4.1.2). This is something that has not been observed in the literature (Carrer et al., 2010b).

The different selection of clear sky instants mentioned in the present manuscript and in the article describing the McClear methodology (Lefèvre et al., 2013) explains most of the differences observed between the McClear's scores in both studies. According to experiments, the methodology proposed in this study (see Sect. 2.4) considers many mildly or highly aerosol-polluted (yet clear) instants of time that may have been ruled out in (Lefèvre et al., 2013), in which a different filtering strategy was used (see Sect. 3.1.2). The different sensitivity between the two clear sky selections 
may explain the lower DSSF averages and higher RMSE obtained for McClear over some stations in the present article in comparison with (Lefèvre et al., 2013). This thesis is supported by the fact that differences are significant only for stations with high AOD values. For example, average RMSE for McClear-estimated direct DSSF in the dusty station of Tamanrasset (Sede Boqer) is $82.3 \mathrm{~W} \mathrm{~m}^{-2}\left(71.8 \mathrm{~W} \mathrm{~m}^{-2}\right)$ in our manuscript and $48 \mathrm{~W} \mathrm{~m}^{-2}\left(62 \mathrm{~W} \mathrm{~m}^{-2}\right)$ in Lefèvre et al. (2013). However, both studies obtained similar results in the less aerosol-affected site of Carpentras $\left(33.6 \mathrm{~W} \mathrm{~m}^{-2}\right.$ in our manuscript and $35 \mathrm{~W} \mathrm{~m}^{-2}$ in Lefèvre et al., 2013).

Regarding the use of MACC-II analyses to characterize aerosol conditions, Experiment 5 points out the significant decrease of the accuracy of the estimated DSSF if MACCII forecast data is used instead of the reanalyses. In this case, the performances of SIRAMix in estimating global DSSF become similar to those of the current LSA-SAF product. This outcome may argue against the use of SIRAMix in an operational configuration for which near real time inputs are necessary. On the other hand, the accuracy obtained with SIRAMix using MACC-II reanalyses is much better, but still slightly below the outcomes of the accuracy assessment carried out with libRadtran simulations in Experiment 1. This is mostly due to the uncertainties affecting the input data, which are especially important for the aerosol information. This is confirmed by the occurrence of the worst DSSF accuracy for stations with highly varying aerosol conditions such as the desert stations of Sede Boqer and Tamanrasset (see Experiment 5), which are not sufficiently well reproduced by the reanalyzed MACC-II data. It is important to remark here that MODIS observations of total AOD are usually not available over deserts, therefore making the aerosol assimilation carried out in the MACC-II system impossible. This can affect the quality of the aerosol analysis over Sede Boqer and Tamanrasset. Given the high sensitivity of DSSF to the quality of aerosol inputs (see Experiment 2), uncertainties in aerosol properties from MACC-II may be still too large to properly estimate DSSF in some cases. Therefore, more efforts will be needed in the future to obtain a better characterization of aerosol particles.

The combination in SIRAMix of a physical parameterization and a pre-computed LUT presents some advantages beyond computational efficiency (more than 150 times faster than libRadtran). First, the flexibility of the parameterization allows it, for example, to calculate the atmospheric radiative forcing at the surface due to a given atmospheric component (see Experiment 6). Second, the approach developed in Ceamanos et al. (2014) to account for mixtures of aerosol species (see Section 2.2.2) can be easily implemented with a parameterization-based method. Finally, the use of a LUT is adopted to store the radiative properties of each aerosol component, as analytical equations for such quantities do not exist and are not straightforward to derive.

Eventually, it is interesting to stress the dependence of aerosol radiative quantities in the SIRAMix LUT on water vapor content, thus taking into account the hygroscopicity of aerosol particles such as the prevailing sulfate particles (Wang and Martin, 2007). Further investigation will be conducted in the future to study the impact of aerosol hygroscopicity on DSSF and the influence of relative humidity on aerosol radiative forcing (Markowicz et al., 2003).

\section{Conclusions}

A new approach referred to as SIRAMix is proposed in this article to estimate the instantaneous global, direct, and diffuse downwelling surface shortwave flux under clear sky conditions. The combination of a pre-computed look up table of aerosol radiative quantities with an accurate physical parameterization allows SIRAMix to efficiently compute DSSF according to a given atmospheric situation. The main novelty of SIRAMix compared to the current state of the art in DSSF retrieval is the consideration of an aerosol layer made of several aerosol species that are differently combined to reproduce any aerosol situation on Earth. In this article, SIRAMix is tested using atmospheric fields from the ECMWF as inputs, among other data. In particular, MACCII analyses of aerosol content and type are used to characterize the aerosol conditions for a given location and time. The proposed method is found to provide highly accurate DSSF estimates with regard to ground measurements and others retrieval approaches. In addition to the estimation of DSSF, SIRAMix may be used to investigate the atmospheric radiative forcing at the surface level. This additional asset of SIRAMix comes from the proximity of this work to the modeling of the atmospheric direct effect. In this context, the study of the effects of aerosols upon climate could be carried out by SIRAMix through the spatio-temporal quantification of aerosol surface radiative forcing (Ramanathan et al., 2001). Also, SIRAMix provides a tool to investigate other topics like, for example, the impact of water vapor or carbon dioxide on the increase of surface temperature and its relation to greenhouse effects (Solomon et al., 2010; Zhang et al., 2013). Nevertheless, this additional capability of SIRAMix deserves a more complete assessment to be done in the future, as this article has been purposely focused on the estimation of diffuse and direct DSSF. Finally, it is important to note that only the use of MACC-II aerosol reanalyses provided significant improvements in terms of global DSSF in comparison with the LSA-SAF current DSSF product. Indeed, the combination of SIRAMix with MACC-II AOD forecasts resulted in less accurate DSSF retrievals. This outcome will be taken into account in the forthcoming implementation of SIRAMix in the operational system of the LSA-SAF project to produce global, direct, and diffuse DSSF in near real time. While forecast MACC-II data will be used for the operational near real time LSA-SAF processing chain, reanalyzed MACC-II data will be used for the periodical reanalyses done in the LSA-SAF project. 
Appendix A: Global Aerosol Data Set

Table A1. List of GADS aerosol components. Data are borrowed from Koepke et al. (1997) and Hess et al. (1998). Parameter $r_{\text {mod } V}(\mu \mathrm{m})$ is the mode radius of the volume distribution.

\begin{tabular}{lrrrrrrrr}
\hline $\begin{array}{l}\text { Aerosol component } \\
\text { Description }\end{array}$ & $\begin{array}{r}\text { INSO } \\
\text { insoluble }\end{array}$ & $\begin{array}{r}\text { WASO } \\
\text { water- } \\
\text { soluble }\end{array}$ & $\begin{array}{r}\text { SOOT } \\
\text { soot }\end{array}$ & $\begin{array}{r}\text { SSAM } \\
\text { sea salt } \\
\text { (fine) }\end{array}$ & $\begin{array}{r}\text { SSCM } \\
\text { sea salt } \\
\text { (coarse) }\end{array}$ & $\begin{array}{r}\text { MINM } \\
\text { mineral } \\
\text { (fine) }\end{array}$ & $\begin{array}{r}\text { MIAM } \\
\text { mineral } \\
\text { (medium) }\end{array}$ & $\begin{array}{r}\text { MICM } \\
\text { Mineral } \\
\text { (coarse) }\end{array}$ \\
\hline$\omega_{0}$ at $500 \mathrm{~nm}$ & 0.72 & 0.98 & 0.23 & 1.0 & 1.0 & 0.95 & 0.83 & 0.62 \\
$g$ at $500 \mathrm{~nm}$ & 0.84 & 0.68 & 0.35 & 0.78 & 0.82 & 0.67 & 0.76 & 0.87 \\
$r_{\bmod V}(\mu \mathrm{m})$ & 6.00 & 0.15 & 0.05 & 0.94 & 7.90 & 0.27 & 1.60 & 11.0 \\
Hygroscopic & no & yes & no & yes & yes & no & no & no \\
\hline
\end{tabular}

The Global Aerosol Data Set (GADS) provides optical properties for several aerosol components that are representative for the Earth's atmosphere. This data base is widely used in many studies to model aerosol radiative properties (Hess et al., 1998; Perrone et al., 2012). Table A1 summarizes the GADS components that are used in the proposed method SIRAMix to characterize the five-component aerosol layer. Two and three aerosol components with different average particle size are available for sea salt and dust particles, respectively (see $r_{\bmod V}$ in Table A1). Note the different extinction properties of each component as it is shown by the single scattering albedo $\left(\omega_{0}\right)$ and asymmetry factor $(g)$.

\section{Appendix B: Processing of MACC-II AOD data}

\section{B1 From MACC-II to GADS-based aerosol components}

The AOD values corresponding to the five aerosol components in MACC-II (i.e., SU, OM, BC, DU, SS) are assigned to the five GADS-based components used in SIRAMix (i.e., INSO, WASO, SOOT, SSALL, MIALL) as follows

$$
\begin{aligned}
& \delta_{0}^{\mathrm{WASO}}=\delta_{0}^{\mathrm{SU}}+0.5 \delta_{0}^{\mathrm{OM}}+0.2 \delta_{0}^{\mathrm{BC}}, \\
& \delta_{0}^{\mathrm{INSO}}=0.5 \delta_{0}^{\mathrm{OM}}, \\
& \delta_{0}^{\mathrm{SOOT}}=0.8 \delta_{0}^{\mathrm{BC}}, \\
& \delta_{0}^{\mathrm{SSALL}}=\delta_{0}^{\mathrm{SS}} \\
& \delta_{0}^{\mathrm{MIALL}}=\delta_{0}^{\mathrm{DU}} .
\end{aligned}
$$

The AOD for MACC-II component OM must be split according to the hygroscopicity of its particles, as organic matter in MACC-II is considered to be $50 \%$ hydrophobic and $50 \%$ hygroscopic (Morcrette et al., 2009). Similarly, the AOD corresponding to the MACC-II component BC is split in two parts as MACC-II considers black carbon particles to be $80 \%$ hydrophobic (assigned to GADS component SOOT) and $20 \%$ hygroscopic (assigned to GADS component WASO). It is worth remembering here that GADS component SOOT is defined as totally hydrophobic (see Table A1). The totality of the AOD corresponding to the MACC-II component SU is assigned to the GADS component WASO, as sulfate particles are $100 \%$ hygroscopic.

The appropriateness of this conversion of AOD values is in agreement with the fact that optical properties of sulfates (SU), organic matter (OM), and black carbon (BC) in MACC-II are taken from GADS components WASO, INSO, and SOOT, respectively (Morcrette et al., 2009). On the other hand, sea salt particles in both GADS (i.e., SSAM and SSCM) and MACC-II (i.e., SS) are described according to (Shettle and Fenn, 1979). Eventually, dust particles in MACC-II (i.e., DU) are modeled following (Dubovik et al., 2002), who conclude that aerosol properties observed with the AERONET network largely agree with GADS dust properties (i.e., MIAM, MINM, MICM).

\section{B2 Height correction of MACC-II aerosol data}

The proposed method SIRAMix considers that aerosols are vertically distributed from the ground height $\left(H_{0}\right)$ to the top boundary of the aerosol layer $\left(H_{\mathrm{TOL}}\right)$ (see Fig. 1$)$ following an exponential distribution

$N(h)=N(0) e^{-\frac{h}{Z}}$, 
where $Z$ is the scale height in kilometers and $N(h)$ is the density in number of particles $\left(\mathrm{cm}^{-3}\right)$ at the given height $h$. Table B1 lists the parameters describing the vertical structure for each GADS-based aerosol component according to Koepke et al. (1997).

Knowing that aerosol optical depth at the ground can be computed as (Hess et al., 1998)

$\delta_{0}=\kappa^{1} \int_{H_{0}}^{H_{\mathrm{TOL}}} N(h) \mathrm{d} h$,

where $\kappa^{1}$ is the particle number cross section, it can be rewritten using Eq. (B2) as

$\delta_{0}=\kappa^{1} \int_{H_{0}}^{H_{\mathrm{TOL}}} N(0) e^{-\frac{h}{Z}} \mathrm{~d} h$,

and solving for the integral

$\delta_{0}=\kappa^{1} N(0) Z\left(e^{-\frac{H_{0}}{Z}}-e^{-\frac{H_{\mathrm{TOL}}}{Z}}\right)$.

Analogously, the AOD at the altitude of a given MACC-II pixel $\left(H_{0, \text { MACC }}\right)$ reads

$\delta_{0, \mathrm{MACC}}=\kappa^{1} N(0) Z\left(e^{-\frac{H_{0, \mathrm{MACC}}}{Z}}-e^{-\frac{H_{\mathrm{TOL}}}{Z}}\right)$,

resulting in the following expression to correct MACC-II AOD values for height difference with the real ground altitude

$\delta_{0}=\delta_{0, \mathrm{MACC}}\left(e^{-\frac{H_{0}}{Z}}-e^{-\frac{H_{\mathrm{TOL}}}{Z}}\right)\left(e^{-\frac{H_{0, \mathrm{MACC}}}{Z}}-e^{-\frac{H_{\mathrm{TOL}}}{Z}}\right)^{-1}$.
Table B1. Parameters defining the vertical structure $\left(Z\right.$ and $\left.H_{\mathrm{TOL}}\right)$ of each GADS-based aerosol component in SIRAMix are given. Also, coefficients for the conversion of AOD at $550 \mathrm{~nm}$ to the shortwave range ( $\alpha$ and $\beta$ ) are given for each aerosol component to complete Eq. (B8).

\begin{tabular}{lrrrrr}
\hline $\begin{array}{l}\text { Aerosol } \\
\text { component }\end{array}$ & INSO & WASO & SOOT & SSALL & MIALL \\
\hline$Z(\mathrm{~km})$ & 8 & 8 & 8 & 1 & 2 \\
$H_{\mathrm{TOL}}(\mathrm{km})$ & 2 & 2 & 2 & 2 & 6 \\
$\alpha$ & 0.002 & 0.057 & 0.047 & 0.009 & 0.002 \\
$\beta$ & 1.022 & 0.646 & 0.711 & 0.961 & 0.977 \\
\hline
\end{tabular}

The adoption of an exponential vertical profile for aerosol concentration represents the main weakness of this strategy. Indeed, real vertical profiles might not correspond to Eq. (B2). However, sensitivity studies showed that inaccuracies resulting from using an incorrect vertical aerosol profile were greatly lower (less than $5 \mathrm{~W} \mathrm{~m}^{-2}$ bias on global DSSF) than those resulting from a $10 \%$ biased AOD (up to $30 \mathrm{~W} \mathrm{~m}^{-2}$ bias) for standard aerosol conditions $(\mathrm{AOD}=0.2)$. Given that MACC-II aerosol data may be often biased by more than $10 \%$ (Cesnulyte et al., 2014), we concluded that the aerosol vertical profile is not a first-order parameter in the estimation of DSSF and that the exponential vertical distribution in Eq. (B2) is therefore accurate enough for our purposes. This point will be further investigated in the future along with the likely improvement of the MACC-II aerosol load estimates by the ECMWF.

\section{B3 Broadband conversion of spectral AOD}

Values of AOD at $550 \mathrm{~nm}\left(\delta_{0}\right)$ are converted into the shortwave range $\left(\Delta_{0}\right)$ following

$\Delta_{0}=-\alpha\left(\delta_{0}\right)^{2}+\beta \delta_{0}$,

where $\alpha$ and $\beta$ are coefficients obtained from regression of libRadtran simulations and are valid for optical depths up to 4. Table B1 lists the coefficients for each aerosol component used in SIRAMix. 
Acknowledgements. First of all, the authors feel indebted to S. Coelho (IPMA) for providing us with the MACC-II data used in this study. Also, we would like to thank the McClear team for making their product available. The BSRN team, the AEMET service, and the LSA-SAF colleagues from KIT are also acknowledged for providing the ground DSSF measurements used for validation. We thank the libRadtran team for their assistance in using their software and J.-J. Morcrette for his help in understanding the AOD data generated in MACC-II. Finally, we would like to thank the two reviewers that revised our work for their sound and useful comments. One of us (X. Ceamanos) was supported by EUMETSAT in the framework of the LSA-SAF project.

Edited by: R. Engelen

\section{References}

Anderson, G. P., Clough, S. A., Kneizys, F. X., Chetwynd, J. H., and Shettle, E. P.: AFGL atmospheric constituent profiles (0120 km), AFGL-TR-86-0110, Tech. rep., Air Force Geophysics Laboratory, Massachusetts, 1986.

Andreae, M. O.: Chapter 10 Climatic effects of changing atmospheric aerosol levels, in: Future climates of the world: a modelling perspective, edited by: Henderson-Sellers, A., World Survey of Climatology, 16, 347-398, doi:10.1016/S01686321(06)80033-7, 1995.

Behnert, I., Matthias, V., and Doerffer, R.: Aerosol climatology from ground-based measurements for the southern North Sea, Atmos. Res., 84, 201-220, doi:10.1016/j.atmosres.2006.05.006, 2007.

Bellouin, N., Quaas, J., Morcrette, J.-J., and Boucher, O.: Estimates of aerosol radiative forcing from the MACC re-analysis, Atmos. Chem. Phys., 13, 2045-2062, doi:10.5194/acp-13-20452013, 2013.

Benedetti, A., Morcrette, J.-J., Boucher, O., Dethof, A., Engelen, R. J., Fisher, M., Flentje, H., Huneeus, N., Jones, L., Kaiser, J. W., Kinne, S., Mangold, A., Razinger, M., Simmons, A. J., and Suttie, M.: Aerosol analysis and forecast in the European Centre for Medium-Range Weather Forecasts Integrated Forecast System: 2. Data assimilation, J. Geophys. Res.-Atmos., 114, D13205, doi:10.1029/2008JD011115, 2009.

Bevan, S. L., North, P. R., Los, S. O., and Grey, W. M.: A global dataset of atmospheric aerosol optical depth and surface reflectance from AATSR, Remote Sens. Environ., 116, 199-210, doi:10.1016/j.rse.2011.05.024, 2012.

Bi, J., Huang, J., Fu, Q., Ge, J., Shi, J., Zhou, T., and Zhang, W.: Field measurement of clear-sky solar irradiance in Badain Jaran Desert of Northwestern China, J. Quant. Spectrosc. Ra., 122, 194-207, doi:10.1016/j.jqsrt.2012.07.025, 2013.

Bird, R. and Hulstrom, R.: A Simplified Clear Sky Model for Direct and Diffuse Insolation on Horizontal Surfaces. SERI/TR-642761, Tech. rep., Solar Energy Research Institute (SERI/NREL), Colorado, 1981.

Bush, B. C. and Valero, F. P. J.: Surface aerosol radiative forcing at Gosan during the ACE-Asia campaign, J. Geophys. Res.-Atmos., 108, 8660, doi:10.1029/2002JD003233, 2003.

Carrer, D., Roujean, J.-L., Hautecoeur, O., and Elias, T.: Daily estimates of aerosol optical thickness over land surface based on a directional and temporal analysis of SEVIRI
MSG visible observations, J. Geophys. Res., 115, D10208, doi:10.1029/2009JD012272, 2010a.

Carrer, D., Roujean, J. L., and Meurey, C.: Comparing Operational MSG/SEVIRI Land Surface Albedo Products From Land SAF With Ground Measurements and MODIS, IEEE T. Geosci. Remote, 48, 1714-1728, doi:10.1109/TGRS.2009.2034530, $2010 \mathrm{~b}$.

Carrer, D., Lafont, S., Roujean, J.-L., Calvet, J.-C., Meurey, C., Le Moigne, P., and Trigo, I. F.: Incoming Solar and Infrared Radiation Derived from METEOSAT: Impact on the Modeled Land Water and Energy Budget over France, J. Hydrometeorol., 13, 504-550, doi:10.1175/JHM-D-11-059.1, 2012.

Ceamanos, X., Carrer, D., and Roujean, J.-L.: An efficient approach to estimate the transmittance and reflectance of a mixture of aerosol components, Atmos. Res., 137, 125-135, doi:10.1016/j.atmosres.2013.09.009, 2014.

Cesnulyte, V., Lindfors, A. V., Pitkänen, M. R. A., Lehtinen, K. E. J., Morcrette, J.-J., and Arola, A.: Comparing ECMWF AOD with AERONET observations at visible and UV wavelengths, Atmos. Chem. Phys., 14, 593-608, doi:10.5194/acp-14593-2014, 2014.

Deneke, H., Feijt, A., van Lammeren, A., and Simmer, C.: Validation of a Physical Retrieval Scheme of Solar Surface Irradiances from Narrowband Satellite Radiances, J. Appl. Meteorol., 44, 1453-1466, doi:10.1175/JAM2290.1, 2005.

Dentener, F., Kinne, S., Bond, T., Boucher, O., Cofala, J., Generoso, S., Ginoux, P., Gong, S., Hoelzemann, J. J., Ito, A., Marelli, L., Penner, J. E., Putaud, J.-P., Textor, C., Schulz, M., van der Werf, G. R., and Wilson, J.: Emissions of primary aerosol and precursor gases in the years 2000 and 1750 prescribed data-sets for AeroCom, Atmos. Chem. Phys., 6, 4321-4344, doi:10.5194/acp-64321-2006, 2006.

Derrien, M. and Le Gléau, H.: MSG/SEVIRI cloud mask and type from SAFNWC, Int. J. Remote Sens., 26, 4707-4732, doi:10.1080/01431160500166128, 2005.

di Sarra, A., Fuà, D., and Meloni, D.: Estimate of surface direct radiative forcing of desert dust from atmospheric modulation of the aerosol optical depth, Atmos. Chem. Phys., 13, 5647-5654, doi:10.5194/acp-13-5647-2013, 2013.

Dubovik, O., Holben, B., Eck, T. F., Smirnov, A., Kaufman, Y. J., King, M. D., Tanré, D., and Slutsker, I.: Variability of Absorption and Optical Properties of Key Aerosol Types Observed in Worldwide Locations, J. Atmos. Sci., 59, 590-608, doi:10.1175/15200469(2002)059<0590:VOAAOP>2.0.CO;2, 2002.

Geiger, B., Carrer, D., Franchistéguy, L., Roujean, J. L., and Meurey, C.: Land surface albedo derived on a daily basis from Meteosat Second Generation observations, IEEE T. Geosci. Remote, 46, 3841-3856, doi:10.1109/TGRS.2008.2001798, 2008a.

Geiger, B., Meurey, C., Lajas, D., Franchistéguy, L., Carrer, D., and Roujean, J.-L.: Near real-time provision of downwelling shortwave radiation estimates derived from satellite observations, Meteorol. Appl., 15, 411-420, doi:10.1002/met.84, 2008 b.

Gueymard, C. A.: Direct solar transmittance and irradiance predictions with broadband models. Part I: detailed theoretical performance assessment, Sol. Energy, 74, 355-379, doi:10.1016/S0038-092X(03)00195-6, 2003.

Hess, M., Koepke, P., and Schult, I.: Optical Properties of Aerosols and Clouds: The Software Package OPAC, B. Am. Meteorol. Soc., 79, 831-844, doi:10.1175/15200477(1998)079<0831:OPOAAC>2.0.CO;2, 1998. 
Holben, B., Eck, T., Slutsker, I., Tanré, D., Buis, J., Setzer, A., Vermote, E., Reagan, J., Kaufman, Y., Nakajima, T., Lavenu, F., Jankowiak, I., and Smirnov, A.: AERONET - A Federated Instrument Network and Data Archive for Aerosol Characterization, Remote Sens. Environ., 66, 1-16, doi:10.1016/S00344257(98)00031-5, 1998

Ineichen, P., Barroso, C. S., Geiger, B., Hollmann, R., Marsouin, A., and Mueller, R.: Satellite Application Facilities irradiance products: hourly time step comparison and validation over Europe, Int. J. Remote Sens., 30, 5549-5571, doi:10.1080/01431160802680560, 2009.

Israelevich, P., Ganor, E., Alpert, P., Kishcha, P., and Stupp, A.: Predominant transport paths of Saharan dust over the Mediterranean Sea to Europe, J. Geophys. Res., 117, D02205, doi:10.1029/2011JD016482, 2012.

Kasten, F. and Young, A. T.: Revised optical air mass tables and approximation formula, Appl. Optics, 28, 4735-4738, doi:10.1364/AO.28.004735, 1989.

Koepke, P., Hess, M., Schult, I., and Shettle, E. P.: Global Aerosol Data Set, Tech. Rep. 243, Max-Planck-Institut für Meteorologie, Hamburg, 1997.

Kokhanovsky, A. A., Mayer, B., and Rozanov, V. V.: A parameterization of the diffuse transmittance and reflectance for aerosol remote sensing problems, Atmos. Res., 73, 37-43, doi:10.1016/j.atmosres.2004.07.004, 2005.

Lacis, A. A. and Hansen, J.: A Parameterization for the Absorption of Solar Radiation in the Earth's Atmosphere, J. Atmos. Sci., 31, 118-133, doi:10.1175/15200469(1974)031<0118:APFTAO>2.0.CO;2, 1974.

Lefèvre, M., Oumbe, A., Blanc, P., Espinar, B., Gschwind, B., Qu, Z., Wald, L., Schroedter-Homscheidt, M., Hoyer-Klick, C., Arola, A., Benedetti, A., Kaiser, J. W., and Morcrette, J.-J.: McClear: a new model estimating downwelling solar radiation at ground level in clear-sky conditions, Atmos. Meas. Tech., 6, 2403-2418, doi:10.5194/amt-6-2403-2013, 2013.

Liang, S., Zhao, X., Liu, S., Yuan, W., Cheng, X., Xiao, Z., Zhang, X., Liu, Q., Cheng, J., Tang, H., Qu, Y., Bo, Y., Qu, Y., Ren, H., Yu, K., and Townshend, J.: A long-term Global LAnd Surface Satellite (GLASS) data-set for environmental studies, International Journal of Digital Earth, 6, 5-33, doi:10.1080/17538947.2013.805262, 2013.

Mallet, M., Pont, V., Liousse, C., Roger, J., and Dubuisson, P.: Simulation of aerosol radiative properties with the ORISAM-RAD model during a pollution event (ESCOMPTE 2001), Atmos. Environ., 40, 7696-7705, doi:10.1016/j.atmosenv.2006.08.031, 2006.

Mangold, A., De Backer, H., De Paepe, B., Dewitte, S., Chiapello, I., Derimian, Y., Kacenelenbogen, M., Léon, J.-F., Huneeus, N., Schulz, M., Ceburnis, D., O’Dowd, C., Flentje, H., Kinne, S., Benedetti, A., Morcrette, J.-J., and Boucher, O.: Aerosol analysis and forecast in the European Centre for Medium-Range Weather Forecasts Integrated Forecast System: 3. Evaluation by means of case studies, J. Geophys. Res.-Atmos., 116, D03302, doi:10.1029/2010JD014864, 2011.

Markowicz, K. M., Flatau, P. J., Quinn, P. K., Carrico, C. M., Flatau, M. K., Vogelmann, A. M., Bates, D., Liu, M., and Rood, M. J.: Influence of relative humidity on aerosol radiative forcing: An ACE-Asia experiment perspective, J. Geophys. Res.-Atmos., 108, 8662, doi:10.1029/2002JD003066, 2003.
Mayer, B. and Kylling, A.: Technical note: The libRadtran software package for radiative transfer calculations - description and examples of use, Atmos. Chem. Phys., 5, 1855-1877, doi:10.5194/acp-5-1855-2005, 2005.

Mengüç, M. and Viskanta, R.: Comparison of radiative transfer approximations for a highly forward scattering planar medium, J. Quant. Spectrosc. Ra., 29, 381-394, doi:10.1016/00224073(83)90111-5, 1983.

Mercado, L. M., Bellouin, N., Sitch, S., Boucher, O., Huntingford, C., Wild, M., and Cox, P. M.: Impact of changes in diffuse radiation on the global land carbon sink, Nature, 458, 1014-1017, doi:10.1038/nature07949, 2009.

Morcrette, J.-J., Boucher, O., Jones, L., Salmond, D., Bechtold, P., Beljaars, A., Benedetti, A., Bonet, A., Kaiser, J. W., Razinger, M., Schulz, M., Serrar, S., Simmons, A. J., Sofiev, M., Suttie, M., Tompkins, A. M., and Untch, A.: Aerosol analysis and forecast in the European Centre for Medium-Range Weather Forecasts Integrated Forecast System: Forward modeling, J. Geophys. Res., 114, D06206, doi:10.1029/2008JD011235, 2009.

Moreno, A., Gilabert, M., Camacho, F., and Martínez, B.: Validation of daily global solar irradiation images from MSG over Spain, Renew. Energ., 60, 332-342, doi:10.1016/j.renene.2013.05.019, 2013.

Mueller, R., Matsoukas, C., Gratzki, A., Behr, H., and Hollmann, R.: The CM-SAF operational scheme for the satellite based retrieval of solar surface irradiance - A LUT based eigenvector hybrid approach, Remote Sens. Environ., 113, 1012-1024, doi:10.1016/j.rse.2009.01.012, 2009.

Oikonomou, E. K. and O'Neill, A.: Evaluation of ozone and water vapor fields from the ECMWF reanalysis ERA-40 during 1991-1999 in comparison with UARS satellite and MOZAIC aircraft observations, J. Geophys. Res.-Atmos., 111, D14109, doi:10.1029/2004JD005341, 2006.

Perrone, M. R., Tafuro, A., and Kinne, S.: Dust layer effects on the atmospheric radiative budget and heating rate profiles, Atmos. Environ., 59, 344-354, doi:10.1016/j.atmosenv.2012.06.012, 2012.

Pinker, R., Frouin, R., and Li, Z.: A review of satellite methods to derive surface shortwave irradiance, Remote Sens. Environ., 51, 108-124, doi:10.1016/0034-4257(94)00069-Y, 1995.

Psiloglou, B., Santamouris, M., and Asimakopoulos, D.: On the atmospheric water vapor transmission function for solar radiation models, Sol. Energy, 53, 445-453, doi:10.1016/0038092X(94)90059-0, 1994.

Psiloglou, B., Santamouris, M., and Asimakopoulos, D.: Predicting the broadband transmittance of the uniformly mixed gases $\left(\mathrm{CO}_{2}, \mathrm{CO}, \mathrm{N}_{2} \mathrm{O}, \mathrm{CH}_{4}\right.$ and $\left.\mathrm{O}_{2}\right)$ in the atmosphere, for solar radiation models, Renew. Energ., 6, 63-70, doi:10.1016/09601481(94)00062-B, 1995a.

Psiloglou, B., Santamouris, M., and Asimakopoulos, D.: On broadband Rayleigh scattering in the atmosphere for solar radiation modelling, Renew. Energ., 6, 429-433, doi:10.1016/09601481(94)00084-J, 1995b.

Psiloglou, B., Santamouris, M., Varotsos, C., and Asimakopoulos, D.: A new parameterization of the integral ozone transmission, Sol. Energy, 56, 573-581, doi:10.1016/0038-092X(96)00030-8, 1996.

Psiloglou, B. E. and Kambezidis, H. D.: Performance of the meteorological radiation model during the solar eclipse of 29 March 
2006, Atmos. Chem. Phys., 7, 6047-6059, doi:10.5194/acp-76047-2007, 2007.

Péré, J., Mallet, M., Pont, V., and Bessagnet, B.: Impact of aerosol direct radiative forcing on the radiative budget, surface heat fluxes, and atmospheric dynamics during the heat wave of summer 2003 over western Europe: A modeling study, J. Geophys. Res., 116, D23119, doi:10.1029/2011JD016240, 2011.

Quintana-Seguí, P., Ribes, A., Martin, E., Habets, F., and Boé, J.: Comparison of three downscaling methods in simulating the impact of climate change on the hydrology of Mediterranean basins, J. Hydrol., 383, 111-124, doi:10.1016/j.jhydrol.2009.09.050, 2010.

Ramanathan, V., Crutzen, P. J., Kiehl, J. T., and Rosenfeld, D.: Aerosols, Climate, and the Hydrological Cycle, Science, 294, 2119-2124, doi:10.1126/science.1064034, 2001.

Roerink, G., Bojanowski, J., de Wit, A., Eerens, H., Supit, I., Leo, O., and Boogaard, H.: Evaluation of MSG-derived global radiation estimates for application in a regional crop model, Agr. Forest Meteorol., 160, 36-47, doi:10.1016/j.agrformet.2012.02.006, 2012.

Roger, J. C., Mallet, M., Dubuisson, P., Cachier, H., Vermote, E., Dubovik, O., and Despiau, S.: A synergetic approach for estimating the local direct aerosol forcing: Application to an urban zone during the Expérience sur Site pour Contraindre les Modèles de Pollution et de Transport d'Emission (ESCOMPTE) experiment, J. Geophys. Res.-Atmos., 111, D13208, doi:10.1029/2005JD006361, 2006.

Schmetz, J., Pili, P., Tjemkes, S., Just, D., Kerkmann, J., Rota, S., and Ratier, A.: An Introduction to Meteosat Second Generation (MSG), B. Am. Meteorol. Soc., 83, 977-992, doi:10.1175/15200477(2002)083<0977:AITMSG>2.3.CO;2, 2002.

Schmidt, K. S., Pilewskie, P., Bergstrom, R., Coddington, O., Redemann, J., Livingston, J., Russell, P., Bierwirth, E., Wendisch, M., Gore, W., Dubey, M. K., and Mazzoleni, C.: A new method for deriving aerosol solar radiative forcing and its first application within MILAGRO/INTEX-B, Atmos. Chem. Phys., 10, 78297843, doi:10.5194/acp-10-7829-2010, 2010.

Sobolev, V. V.: Light scattering in planetary atmospheres (Translation of Rasseianie sveta v atmosferakh planet, Pergamon Press, Oxford and New York, 1975), Izdatel'stvo Nauka, Moscow, 1972.

Solomon, S., Rosenlof, K. H., Portmann, R. W., Daniel, J. S., Davis, S. M., Sanford, T. J., and Plattner, G.-K.: Contributions of Stratospheric Water Vapor to Decadal Changes in the Rate of Global Warming, Science, 327, 1219-1223, doi:10.1126/science.1182488, 2010.

Soon, W. and Legates, D. R.: Solar irradiance modulation of Equator-to-Pole (Arctic) temperature gradients: Empirical evidence for climate variation on multi-decadal timescales, J. Atmos. Sol.-Terr. Phy., 93, 45-56, doi:10.1016/j.jastp.2012.11.015, 2013.
Szczypta, C., Decharme, B., Carrer, D., Calvet, J.-C., Lafont, S., Somot, S., Faroux, S., and Martin, E.: Impact of precipitation and land biophysical variables on the simulated discharge of European and Mediterranean rivers, Hydrol. Earth Syst. Sci., 16, 3351-3370, doi:10.5194/hess-16-3351-2012, 2012.

Trigo, I. F., Dacamara, C. C., Viterbo, P., Roujean, J.-L., Olesen, F., Barroso, C., Camacho-de Coca, F., Carrer, D., Freitas, S. C., García-Haro, J., Geiger, B., Gellens-Meulenberghs, F., Ghilain, N., Meliá, J., Pessanha, L., Siljamo, N., and Arboleda, A.: The Satellite Application Facility for Land Surface Analysis, Int. J. Remote Sens., 32, 2725-2744, doi:10.1080/01431161003743199, 2011.

van Weele, M., Martin, T. J., Blumthaler, M., Brogniez, C., den Outer, P. N., Engelsen, O., Lenoble, J., Pfister, G., Ruggaber, A., Walravens, B., Weihs, P., Dieter, H., Gardiner, B. G., Gillotay, D., Kylling, A., Mayer, B., Seckmeyer, G., and Wauben, W.: From model intercomparisons towards benchmark UV spectra for six real atmospheric cases, J. Geophys. Res., 105, 4915-4925, doi:10.1029/1999JD901103, 2000.

Varotsos, C. A., Ondov, J. M., Cracknell, A. P., Efstathiou, M. N., and Assimakopoulos, M.-N.: Long-range persistence in global Aerosol Index dynamics, Int. J. Remote Sens., 27, 3593-3603, doi:10.1080/01431160600617236, 2006.

Vermote, E. F., Vibert, S., Kilcoyne, H., Hoyt, D., and Zhao, T.: Suspended Matter. Visible/Infrared Imager/Radiometer Suite algorithm theroretical basis document, SBRS Document No Y2390, Tech. rep., Raytheon Systems Company, Information Technology and Scientific Services, Maryland, 2005.

Wang, J. and Martin, S. T.: Satellite characterization of urban aerosols: Importance of including hygroscopicity and mixing state in the retrieval algorithms, J. Geophys. Res.-Atmos., 112, D17203, doi:10.1029/2006JD008078, 2007.

WMO (World Meteorological Organization): Part I, Chapter 8. Measurement of sunshine duration, in: WMO-No. 8 - Guide to Meteorological Instruments and Methods of Observation, WMO, 2006.

Yang, K., Koike, T., and Ye, B.: Improving estimation of hourly, daily, and monthly solar radiation by importing global data sets, Agric. Forest Meteorol., 137, 43-55, doi:10.1016/j.agrformet.2006.02.001, 2006.

Yoshida, S., Ueno, S., Kataoka, N., Takakura, H., and Minemoto, T.: Estimation of global tilted irradiance and output energy using meteorological data and performance of photovoltaic modules, Sol. Energy, 93, 90-99, doi:10.1016/j.solener.2013.04.001, 2013.

Zhang, H., Zhang, R., and Shi, G.: An updated estimation of radiative forcing due to $\mathrm{CO}_{2}$ and its effect on global surface temperature change, Adv. Atmos. Sci., 30, 1017-1024, doi:10.1007/s00376-012-2204-7, 2013. 